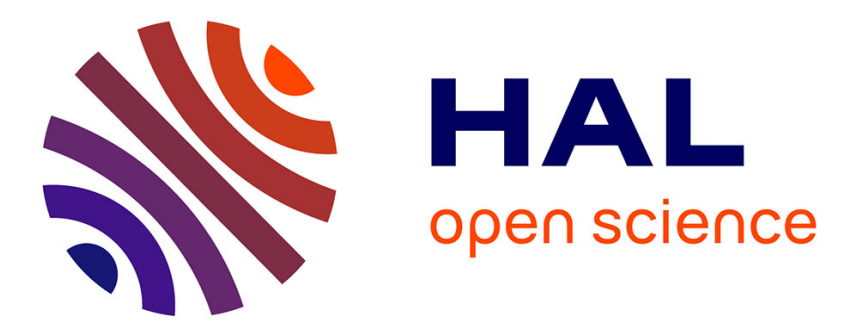

\title{
Projected changes in the Southern Indian Ocean cyclone activity assessed from high-resolution experiments and CMIP5 models
}

\author{
Julien Cattiaux, Fabrice Chauvin, Olivier Bousquet, Sylvie Malardel, \\ Chia-Lun Tsai
}

\section{To cite this version:}

Julien Cattiaux, Fabrice Chauvin, Olivier Bousquet, Sylvie Malardel, Chia-Lun Tsai. Projected changes in the Southern Indian Ocean cyclone activity assessed from high-resolution experiments and CMIP5 models. Journal of Climate, 2020, 33 (12), pp.4975 - 4991. 10.1175/jcli-d-19-0591.1. hal-02516828

\section{HAL Id: hal-02516828 \\ https://hal.science/hal-02516828}

Submitted on 14 Dec 2020

HAL is a multi-disciplinary open access archive for the deposit and dissemination of scientific research documents, whether they are published or not. The documents may come from teaching and research institutions in France or abroad, or from public or private research centers.
L'archive ouverte pluridisciplinaire HAL, est destinée au dépôt et à la diffusion de documents scientifiques de niveau recherche, publiés ou non, émanant des établissements d'enseignement et de recherche français ou étrangers, des laboratoires publics ou privés. 


\title{
Projected Changes in the Southern Indian Ocean Cyclone Activity Assessed from High-Resolution Experiments and CMIP5 Models
}

\author{
JULIEN CATTIAUX AND FABRICE CHAUVIN \\ Centre National de Recherches Météorologiques, Université de Toulouse, CNRS, Météo-France, Toulouse, France \\ Olivier Bousquet, Sylvie MALARDEL, AND CHIA-Lun TSAI \\ Laboratoire de l'Atmosphère et des Cyclones, Université de la Réunion, CNRS, Météo-France, Saint-Denis, France
}

(Manuscript received 2 August 2019, in final form 7 March 2020)

\begin{abstract}
The evolution of tropical cyclone activity under climate change remains a crucial scientific issue. Physical theory of cyclogenesis is limited, observational datasets suffer from heterogeneities in space and time, and state-of-the-art climate models used for future projections are still too coarse ( $\sim 100 \mathrm{~km}$ of resolution) to simulate realistic systems. Two approaches can nevertheless be considered: 1) perform dedicated highresolution (typically $<50 \mathrm{~km}$ ) experiments in which tropical cyclones can be tracked and 2) assess cyclone activity from existing low-resolution multimodel climate projections using large-scale indices as proxies. Here we explore these two approaches with a particular focus on the southern Indian Ocean. We first compute highresolution experiments using the rotated-stretched configuration of our climate model (CNRM-CM6-1), which is able to simulate realistic tropical cyclones. In a $2-\mathrm{K}$ warmer world, the model projects a $20 \%$ decrease in the frequency of tropical cyclones, together with an increase in their maximum lifetime intensity, a slight poleward shift of their trajectories, and a substantial delay (about 1 month) in the cyclone season onset. Largescale indices applied to these high-resolution experiments fail to capture the overall decrease in cyclone frequency, but are able to partially represent projected changes in the spatiotemporal distribution of cyclone activity. Last, we apply large-scale indices to multimodel CMIP5 projections and find that the seasonal redistribution of cyclone activity is consistent across models.
\end{abstract}

\section{Introduction}

Understanding how climate change may influence tropical cyclone (TC) activity remains a challenging scientific issue (Knutson et al. 2010; Walsh et al. 2016). As TCs cause local devastating impacts and play a crucial role in maintaining regional water resources, this question also receives particular public attention.

Detecting potential trends in observational data is limited by the quality of historical records and the difficulty to disentangle the climate change signal from the noise of internal variability. A few studies have analyzed the International Best Track Archive for Climate Stewardship (IBTrACS) database, which compiles the best track datasets from diverse centers (Knapp et al. 2010). Various trends have been reported, such as an increase and a poleward shift in the TC lifetime

Corresponding author: Julien Cattiaux, julien.cattiaux@meteo.fr maximum intensity (Kossin et al. 2013; Holland and Bruyère 2014) or a slowdown of the translation speed (Kossin 2018), but it remains unclear whether these trends result from data heterogeneities (e.g., introduction of new satellites), natural variability, or anthropogenic forcings. Therefore, so far, most assessments regarding the evolution of TCs in a warmer world have been made from theoretical and/or modeling studies.

There is a theoretical expectation that a warmer climate would undergo stronger TCs, in line with higher sea surface temperatures (SST) and increased potential intensity (Emanuel 1988). However, no such robust conclusion exists for changes in TC frequency due to the lack of a generally accepted theory for cyclogenesis, even if progress has been made on identifying the environmental conditions favoring cyclone activity (e.g., Held and Zhao 2011; Peng et al. 2012; Sugi et al. 2012).

Modeling studies addressing the evolution of TCs under climate change face an implacable issue: grid resolution must be high enough to simulate realistic 
TCs and experiments must be long enough—or enroll enough ensemble members-to isolate climate change from natural variability. The current generation of global models used for future climate projections-i.e., participants of the phase 5 of the Coupled Model Intercomparison Project (CMIP5) - have a horizontal grid spacing of about $100 \mathrm{~km}$ or greater (Taylor et al. 2011), which is too coarse to simulate realistic TCs (Camargo 2013); interestingly, the upcoming generation (CMIP6) will include a few models with higher resolutions (typically $50 \mathrm{~km}$ or higher). So far two approaches have thus been traditionally considered for studying TCs: (i) perform additional dedicated experiments at a higher resolution, or (ii) use the existing multimodel low-resolution climate projections to assess how large-scale environmental conditions favorable to cyclone activity may evolve in a warmer climate.

The first approach has been undertaken by a growing, but still limited, number of modeling centers that can afford the computer cost of high-resolution climate projections. Most of the performed experiments project a future reduction in the overall frequency of TCs, but an increase in the frequency of the strongest TCs (Walsh et al. 2016, and references therein). Also commonly reported are projected increases in associated phenomena, such as rainfall amounts and storm surges (Knutson et al. 2015; Woodruff et al. 2013).

The second approach consists of determining statistical relationships between cyclone activity and largescale environmental factors, including dynamical (e.g., vertical and horizontal wind shear, low-tropospheric vorticity) and thermodynamical (e.g., midtropospheric humidity, sea surface temperature) variables. Combinations of these variables allow us to build cyclogenesis indices (CGIs), that have been shown to represent both the seasonal and geographical distribution of cyclone activity fairly well (Menkes et al. 2012). (Previous authors have used the abbreviation "GPIs" as the generic term for these indices, but since "GPI" is also an abbreviation used for one specific index used in this paper, here we use "CGIs.") Using CGIs to quantify potential changes in the cyclone activity is, however, questionable, as it assumes that statistical relationships established for present-day climatological features remain valid in a climate change context. In particular, it has been shown that CGIs fail to capture the decrease in TC frequency when applied to high-resolution climate projections (Camargo et al. 2014; Wehner et al. 2015; Chauvin et al. 2020), which may explain why attempts to apply CGIs to CMIP5 future projections have mostly remained inconclusive so far (Camargo 2013). However, the ability of CGIs to capture other potential changes in the cyclone activity (e.g., changes in the spatiotemporal distribution) has not been documented so far. In addition, since CGIs can be broken down into dynamical and thermal components, they can provide useful insights for the physical understanding of the projected changes in TC tracks.

Here we apply and compare both high-resolution and CGIs approaches to assess projected changes in cyclone activity and explore whether the two approaches can be reconciled on some aspects. We use the same methodology as in Chauvin et al. (2020) but we focus over the SIO basin, which has been seldom studied so far. Among the eight IBTrACS basins, it ranks third in terms of overall number of reported TCs (after the western and eastern Pacific basins). Even if less highly populated regions are exposed to TC hazards than in other basins, SIO TCs can still have dramatic impacts in Western Australia and southeastern Africa, including Madagascar and the Mascarene Islands (La Réunion, Mauritius, and Rodrigues), as recently illustrated by the devastating cyclone Idai. ${ }^{1}$ In the western part of the SIO, the death toll associated with TCs averages to 20 fatalities per year over the last 19 years with 9 seasons above 100 fatalities according to the European Commission Joint Research Centre. $^{2}$ Long-term climate trend analysis in the SIO basin is particularly challenging due to the introduction of the Meteosat-5 geostationary satellite into the region in 1998, which causes a temporal heterogeneity in observational and reanalysis products (Kuleshov et al. 2010; Kossin et al. 2013). Evidences for an observed increase in the number of severe TC days have nevertheless been reported in the western part of the SIO (Kuleshov et al. 2010; Malan et al. 2013). Highresolution climate projections suggest that SIO TCs follow the global behavior: a decrease in the overall frequency and an increase in the intensity (e.g., Murakami et al. 2012; Walsh et al. 2016).

The paper is structured as follows. Observations, reanalyses, high-resolution experiments, and CMIP5 models used in this study are presented in section 2. Methodologies including the tracking algorithm applied to high-resolution data and the cyclogenesis indices applied to lower-resolution data are detailed in section 3. Section 4 contains our main findings while discussion and conclusions are provided in sections 5 and 6.

\footnotetext{
${ }^{1}$ https://public.wmo.int/en/media/news/tropical-cyclone-idaihits-mozambique.

${ }^{2}$ Emergency Reporting 23: http://www.gdacs.org/Public/download. aspx?type $=$ DC\&id $=161$.
} 
TABLE 1. Observations, reanalyses, and CNRM-CM experiments used in this study. Time periods correspond to Southern Hemisphere convention for cyclone seasons (i.e., 1980 is July 1979-June 1980).

\begin{tabular}{cllcc}
\hline \hline Abbreviation & \multicolumn{1}{c}{ Name } & \multicolumn{1}{c}{ Details } & Resolution $(\mathrm{km})$ & Time period \\
\hline IBTr & IBTrACS & TC track observations & - & $1980-2016$ \\
ERAI & ERA-Interim & Reanalysis & 80 & $1980-2016$ \\
ERA5 & ERA-5 & Reanalysis & 30 & $1980-2016$ \\
T127 & CNRM-CM5 & Historical simulation & 155 & $1976-2005$ \\
T359 & CNRM-CM6-HR & AMIP simulation & 55 & $1980-2010$ \\
SIO-P & CNRM-CM6-HR r.-s. & Experiment forced by historical SST & $10-50$ & $1971-2014$ \\
SIO-F & CNRM-CM6-HR r.-s. & Experiment forced by RCP8.5 SST & $10-50$ & $2051-94$ \\
\hline
\end{tabular}

\section{Data}

\section{a. Observations and reanalyses}

Observations and reanalyses used in this study are summarized in Table 1. Observational TC data are taken from the IBTrACS, version 4, dataset released in April 2019 that provides best track characteristics (e.g. position, sea level pressure, maximum sustained winds) on a 3-hourly basis (https://www.ncdc.noaa.gov/ibtracs/, Knapp et al. 2010). For consistency with model and reanalysis data used in this study, we restrict IBTrACS data to the period July 1979-June 2016 (i.e., cyclone seasons 1980-2016) and the hours 0000, 0600, 1200, and 1800 UTC. We only use information provided by the World Meteorological Organization (WMO) Regional Specialized Meteorological Centres (RSMCs): MétéoFrance La Réunion and the Australian Bureau of Meteorology (BoM) for the SIO basin. We only consider systems that are indicated as "TS" (tropical storms) in the metadata and that reach the official moderate tropical storm (category 1) stage according to Météo-France (BoM) classifications (i.e., 10-min sustained winds above $18 \mathrm{~m} \mathrm{~s}^{-1}$ ) at least once in their lifetime. (Note that we use the terminology of the local RSMCs in this paper, not the Saffir-Simpson scale.)

ERA-5 data (30-km resolution, Hersbach et al. 2018) are used for both TC tracking and computing CGIs. ERA-Interim data (80-km resolution, Dee et al. 2011) are also used for computing CGIs, which allows for a fair comparison with CMIP5 models as they do no simulate realistic TCs (contrarily to ERA-5). Both datasets are downloaded from the European Centre for MediumRange Weather Forecasts (https://www.ecmwf.int/en/ forecasts/datasets/browse-reanalysis-datasets), on a regular $0.5^{\circ} \times 0.5^{\circ}$ longitude-latitude grid and at a 6-hourly frequency over the period July 1979-June 2016 (i.e., cyclone seasons 1980-2016).

\section{b. High-resolution experiments}

We use the same experimental setup as in Chauvin et al. (2020), which consists in performing atmosphere-only present-day and future experiments with the Centre National de Recherches Météorologiques Coupled Global Climate Model (CNRM-CM) in its rotatedstretched configuration. The atmospheric component of CNRM-CM (ARPEGE) has indeed the particularity to enable a deformation of its horizontal grid: the pole can be placed over a location of interest (here, the SIO), and a stretching factor can be applied to progressively increase (decrease) the resolution around the pole (the antipode). The advantage of this configuration is that it provides high-resolution simulations over the area of interest, while preserving the consistency of the largescale dynamics between global and regional scales. This technique has been extensively validated as it is routinely utilized by Météo-France for operational numerical weather prediction over Europe and has also been used in numerous studies of TCs over the North Atlantic basin (e.g., Chauvin et al. 2006; Daloz et al. 2012; Chauvin et al. 2020).

In the present study, the stretching is applied to a T359 grid $(720 \times 360$ points $)$, the pole is located at $12.5^{\circ} \mathrm{S}$, $55^{\circ} \mathrm{E}$, and the stretching factor is 3.5 , resulting in a 14-50-km effective resolution within the SIO domain (defined as $0^{\circ}-30^{\circ} \mathrm{S}, 30^{\circ}-120^{\circ} \mathrm{E}$; see Fig. 1a). The choice of the exact grid pole location was made in order to have the highest-resolution increase in the area under the responsibility of the Météo-France RSMC on La Réunion Island. The model is run with a 15-min time step. We use the same version of ARPEGE as in Chauvin et al. (2020) (i.e., a version close to the one participating to CMIP6 through CNRM-CM6-1 and CNRM-ESM2 models). A comprehensive description of this version, including details on convection, microphysics, and turbulence parameterizations, can be found in Voldoire et al. (2019), together with an evaluation of the CNRM-CM6-1 model.

Similarly to Chauvin et al. (2020), two experiments are conducted with the rotated-stretched configuration: a present-day simulation over the period 1971-2014 (named SIO-P), using historical SST and radiative forcings, and a future simulation over the period 2051-94 


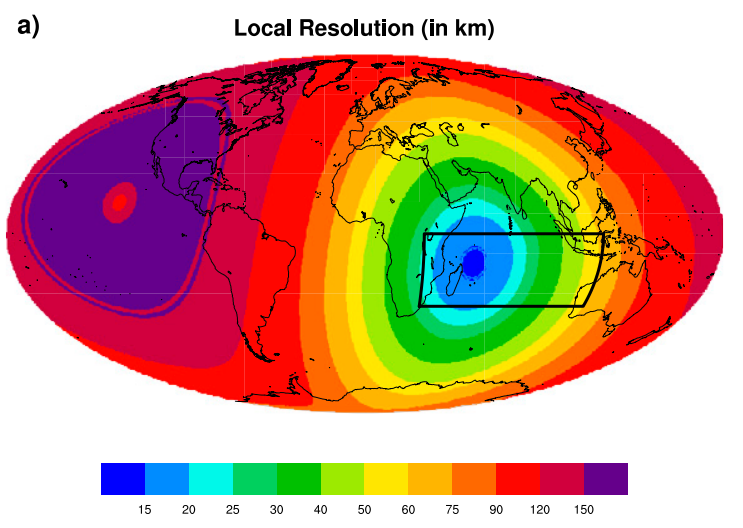

b) SIO-F SST (difference wrt. SIO-P)

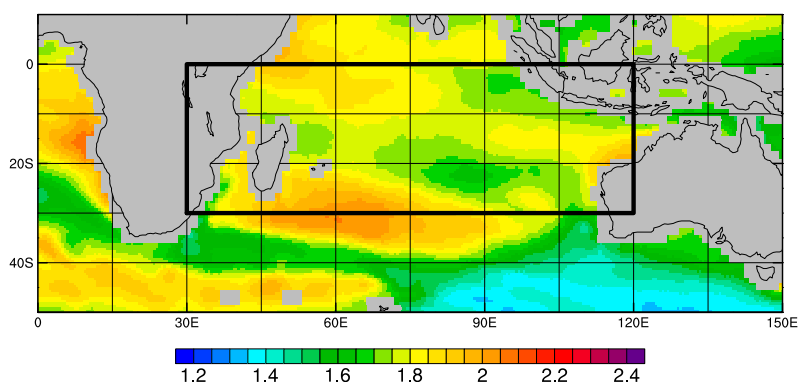

FIG. 1. (a) Effective grid resolution $(\mathrm{km})$ of the rotatedstretched experiments. (b) Mean difference between prescribed SST (K) of SIO-F and SIO-P experiments.

(named SIO-F), using future SST and radiative forcings corresponding to the $8.5 \mathrm{~W} \mathrm{~m}^{-2}$ radiative concentration pathway (RCP8.5). Prescribed SST are taken from a member of CNRM-CM5 historical 1 RCP8.5 simulations (namely, the run r1i1p1; Voldoire et al. 2013), and are bias corrected over the present-day period with respect to the HadISST dataset (Rayner et al. 2003). Further methodological details, including the treatment of sea ice, are provided in Chauvin et al. (2020). The time-averaged SST difference between the two experiments is a generalized warming ranging from 1.6 to $2 \mathrm{~K}$ over the SIO domain with a field average of $1.8 \mathrm{~K}$ (Fig. 1b); CNRMCM5 is close to the CMIP5 multimodel mean on this aspect (not shown). To assess the potential benefits of the rotated-stretched configuration in simulating cyclones, a third experiment with a uniform T359 grid (denoted T359) is conducted over 1980-2010 using prescribed SST from HadISST.

\section{c. CMIP5 simulations}

We use monthly outputs of atmospheric temperature (ta), wind (ua, va), specific humidity (hus), convective precipitation (prc), sea level pressure (psl), and sea surface temperature (ts) from the historical + RCP8.5 simulations of 14 CMIP5 models (Table 2). This ensemble includes the CNRM-CM5 simulation from which SST are taken to perform the high-resolution experiments, which will be denoted T127 in the following. All fields are interpolated from the native model grid onto a common $2.5^{\circ} \times 2.5^{\circ}$ longitude-latitude grid prior to any diagnostic computation. This is also the case for ERA-5 and ERA-Interim data when they are compared with CMIP5 data.

\section{Methods}

\section{a. Tracking algorithm}

As in Daloz et al. (2012) and Chauvin et al. (2020), we use the algorithm introduced and detailed in Chauvin et al. (2006) to track TCs in ERA-5 and SIO-P, SIO-F, and T359 experiments. The tracker is applied to 6-hourly outputs, and in this paper all the data are first interpolated onto a common $0.5^{\circ} \times 0.5^{\circ}$ longitude-latitude

TABLE 2. CMIP5 models used in this study.

\begin{tabular}{|c|c|c|c|c|}
\hline Abbreviation & Name & Country & Lon $\times$ lat & Resolution $(\mathrm{km})$ \\
\hline $\mathrm{BCC}$ & BCC-CSM1.1 & China & $2.8^{\circ} \times 2.8^{\circ}$ & 310 \\
\hline СССМА & CanESM2 & Canada & $2.8^{\circ} \times 2.8^{\circ}$ & 310 \\
\hline CNRM & CNRM-CM5 & France & $1.4^{\circ} \times 1.4^{\circ}$ & 155 \\
\hline CSIRO & CSIRO-Mk3.6.0 & Australia & $1.9^{\circ} \times 1.9^{\circ}$ & 210 \\
\hline GFDL & GFDL-ESM2M & United States & $2.0^{\circ} \times 2.5^{\circ}$ & 250 \\
\hline GISS & GISS-E2-R & United States & $2.0^{\circ} \times 2.5^{\circ}$ & 250 \\
\hline INM & INM-CM4 & Russia & $1.5^{\circ} \times 2.0^{\circ}$ & 195 \\
\hline IPSL & IPSL-CM5A-LR & France & $1.9^{\circ} \times 3.8^{\circ}$ & 300 \\
\hline MIROC & MIROC-ESM & Japan & $2.8^{\circ} \times 2.8^{\circ}$ & 310 \\
\hline $\mathrm{MOHC}$ & HadGEM2-ES & United Kingdom & $1.3^{\circ} \times 1.9^{\circ}$ & 180 \\
\hline MPIM & MPI-ESM-LR & Germany & $1.9^{\circ} \times 1.9^{\circ}$ & 210 \\
\hline MRI & MRI-CGCM3 & China & $1.1^{\circ} \times 1.1^{\circ}$ & 120 \\
\hline NCAR & $\mathrm{CCSM} 4$ & United States & $0.9^{\circ} \times 1.3^{\circ}$ & 120 \\
\hline $\mathrm{NCC}$ & NorESM1 & Norway & $1.1^{\circ} \times 1.1^{\circ}$ & 120 \\
\hline
\end{tabular}


grid (i.e., the effective grid of the T359 experiment and the resolution chosen for the download of ERA-5 data) in order to allow for a fair comparison. The tracking algorithm involves three steps:

1) At each time step, grid points potentially concerned by a TC are identified, based on the main criteria that depict TCs: sea level pressure is a local minimum (low pressure system), 850-hPa vorticity exceeds a threshold (strong vortex), 10-m wind speed exceeds a threshold (strong winds), mean $700-300-\mathrm{hPa}$ temperature local anomaly exceeds a threshold (warm core), tangential wind speed is higher at $850 \mathrm{hPa}$ than at $300 \mathrm{hPa}$ (stronger winds at low levels due to the thermal wind relationship), temperature local anomaly is higher at $300 \mathrm{hPa}$ than at $850 \mathrm{hPa}$ (warmer core at high levels). (Thresholds are discussed below.) Note that there is no latitude criterion, so that the detection can potentially occur outside the tropics.

2) TC points identified in step 1 are connected across consecutive time steps to build TC tracks. The association procedure is described in detail in Chauvin et al. (2006).

3) Tracks are completed before and after the TC stage in order to include cyclogenesis and cyclolysis. This is done by relaxing all criteria except vorticity and rerunning the algorithm backward (forward) from the first (last) point of the previously identified TC track. This step also ensures that a system reaching the TC stage twice (or more) in its lifetime is counted as a unique system.

The algorithm is highly sensitive to the thresholds used in step 1 that primarily depend on the data resolution. Here, the thresholds have been calibrated by repeating the tracking procedure on ERA-5 over 201116 with various combinations of thresholds and comparing the resulting tracks to IBTrACS. The retained values are $20 \times 10^{-5} \mathrm{~s}^{-1}$ for vorticity, $13 \mathrm{~m} \mathrm{~s}^{-1}$ for wind speed, and $1 \mathrm{~K}$ for local temperature anomaly. With these values, the algorithm detects most of IBTrACS trajectories in ERA-5, with a limited number of false or missed tracks (see example of cyclone season 2015 in Fig. 2 and further details in section 4). Note that a perfect correspondence between IBTrACS and ERA5 tracks was not expected due to (i) IBTrACS specificities, (ii) potential model errors, and (iii) potential impacts of data assimilation on TCs.

We distinguish three stages in the tracks resulting from the algorithm: the development stage [from the system initiation (or cyclogenesis) to its intensification into a TC], the TC stage (encompassing all TC points with possible temporary interruptions), and the cyclolysis stage (from the last TC point to the end of the track). For consistency, we also distinguish these three stages in
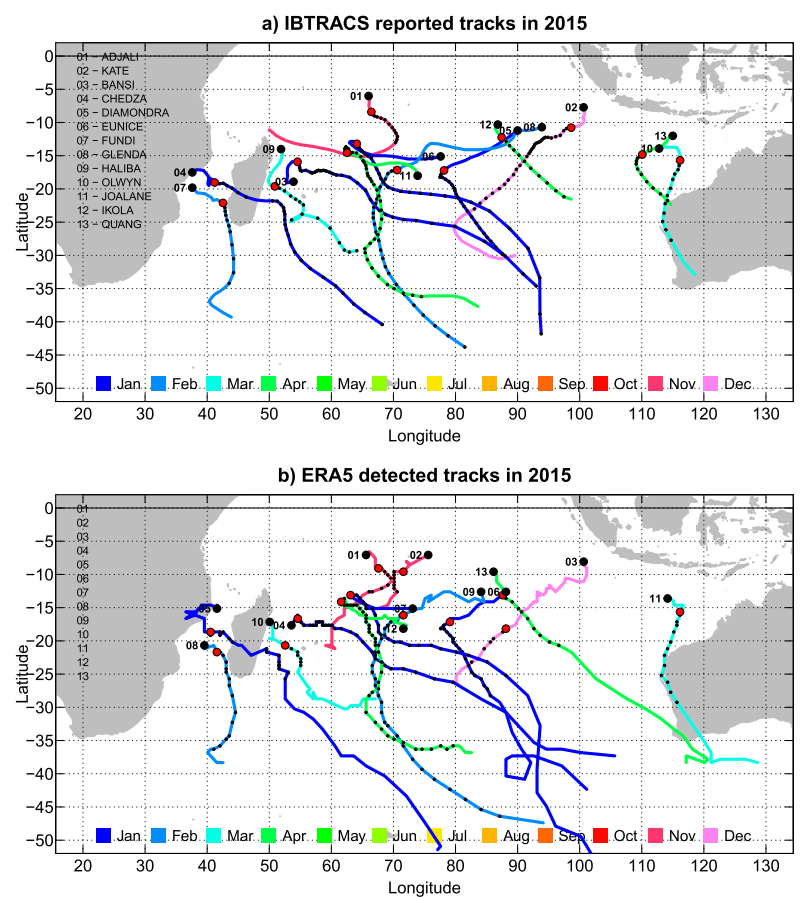

FIG. 2. (a) TC tracks reported in IBTrACS for the 2015 season. (b) TC tracks resulting from the tracking algorithm applied to ERA5 for the 2015 season. Dots along trajectories indicate TC points, with thick black dots for the first point of the system (genesis point) and thick red dots for the first point of the TC stage (intensification point). Track colors indicate the month of the track starting point (genesis).

IBTrACS, but on the basis of the $18 \mathrm{~m} \mathrm{~s}^{-1}$ wind speed threshold: development stage from the track start to the first exceedance, then TC stage until the last exceedance, then cyclolysis stage.

\section{b. Cyclogenesis indices (CGIs)}

The link between cyclone activity and large-scale environmental conditions is assessed using CGIs from the existing literature. We use the three indices evaluated on seasonal and interannual time scales by Menkes et al. (2012), and used separately by Royer and Chauvin (2009), Camargo (2013), and Chauvin et al. (2020) in a climate change perspective:

- the CYGP index introduced by Royer et al. (1998), after Gray (1975);

- the GPI index introduced by Emanuel and Nolan (2004);

- the TCS index introduced by Tippett et al. (2011) (hereafter referred as TIPP in order to avoid confusion with the TCs acronym used for "tropical cyclones").

All indices are computed at the gridpoint scale and on a monthly basis (i.e., calculated with monthly mean climate data). They are constructed as multiplicative functions of dynamical and thermal variables that result 
from empirical fits between observed cyclone activity and reanalyzed large-scale variables. Dynamical variables are the same for the three indices used in this paper (lowlevel vorticity and vertical wind shear) while thermal variables differ. More precisely, the indices are as follows:

$$
\begin{aligned}
\mathrm{CYGP}= & \beta_{\mathrm{CYGP}} \times \underbrace{|f|\left(\zeta \frac{f}{r|f|}+5\right)\left(V_{\text {shear }}+3\right)^{-1}}_{\text {Dhermal }} \\
& \times \underbrace{\max \left(P_{c}^{*-3,0)},\right.}_{\text {Dynamical }} \\
\mathrm{GPI}= & \beta_{\mathrm{GPI}} \times \underbrace{\left|10^{5} \zeta\right|^{3 / 2}\left(1+0.1 V_{\text {shear }}\right)^{-2}}_{\text {Dynamical }} \\
& \times \underbrace{\left(\frac{H}{50}\right)^{3}\left(\frac{V_{\text {pot }}}{70}\right)^{3}}_{\text {Thermal }}, \\
& \times \underbrace{\exp \left(0.05 H+0.56 \mathrm{SSST}_{\text {loc }}\right)}_{\text {TIPP }},
\end{aligned}
$$

where $f$ is the Coriolis parameter, $\varphi$ is the latitude, $\zeta\left(\zeta_{r}\right)$ is the absolute (relative) vorticity at $850 \mathrm{hPa}, V_{\text {shear }}=$ $\Delta V / \Delta p$ is the vertical wind shear between 850 and $200 \mathrm{hPa}, P_{c}^{*}$ is the convective precipitation, $H$ is the relative humidity at $600 \mathrm{hPa}, \mathrm{SST}_{\mathrm{loc}}=\mathrm{SST}-\overline{\mathrm{SST}}^{(20 \mathrm{~S}-20 \mathrm{~N})}$ is the local SST anomaly relative to the tropics $\left(20^{\circ} \mathrm{S}-\right.$ $20^{\circ} \mathrm{N}$ ), and $V_{\text {pot }}$ is the TC potential intensity introduced by Emanuel (1988) that we calculate using the pcmin 2013.f routine distributed by K. Emanuel. ${ }^{3}$ For the three indices, the $\beta$ coefficient is a scaling factor that allows to interpret global maps of CGIs as densities of TCs; here we systematically tune these scaling factors so that the global sum of CGIs equals 84 (TCs per year over the globe) over the present-day period, and we keep the same $\beta$ for computing indices over future periods. More details about the computation of these three indices can be found in the appendix of Menkes et al. (2012).

It is important to note that in this paper, we use the exact same equations for all reanalysis or model data on which we compute CGIs. In particular the numerical constants that are present in the above equations are the ones used by Menkes et al. (2012), and they correspond to the ones originally introduced by the respective authors. Camargo et al. (2014) suggest that CGIs perform better in capturing climate-related changes in cyclone

\footnotetext{
${ }^{3} \mathrm{ftp} / / /$ texmex.mit.edu/pub/emanuel/TCMAX/.
}

activity when they are refitted for the model of interest (including the selection of predictors). Here we consider that such a model-dependent computation of CGIs is outside the scope of our study, and that using the exact same definition for CGIs allows for a fair comparison between models. Last, for the sake of simplicity, results are mainly shown for the average of the three indices (hereafter the aggregate CGI), and behaviors of individual indices are only mentioned in the text when they substantially differ from the mean. Considering the average of CGIs also tends to emphasize signals that are common-thus robust-across individual indices.

As CGIs are written as multiplicative functions, differences between time averages over two periods of time (typically present-day vs future) can be broken down into individual contributions of dynamical versus thermal components. Indeed, for each calendar month, if $x_{i}\left(y_{i}\right)$ denotes the dynamical (thermal) component of the CGI for year $i$, and $x_{i}^{\prime}$ and $y_{i}^{\prime}$ denotes their anomalies relative to their time averages $\bar{x}$ and $\bar{y}$, the time-averaged CGI over either the present-day $(P)$ or the future $(F)$ period is

$$
\overline{\mathrm{CGI}}=\overline{x_{i} y_{i}}=\overline{\left(\bar{x}+x_{i}^{\prime}\right)\left(\bar{y}+y_{i}^{\prime}\right)}=\bar{x} \bar{y}+\overline{x_{i}^{\prime} y_{i}^{\prime}} .
$$

Thus, the $F-P$ difference (denoted $\Delta$ ) in time-averaged CGI is

$$
\Delta \overline{\mathrm{CGI}}=\overline{\mathrm{CGI}}^{F}-\overline{\mathrm{CGI}}^{P}=\bar{x}^{F} \bar{y}^{F}-\bar{x}^{P} \bar{y}^{P}+\underbrace{{\overline{x_{i}^{\prime} y_{i}^{\prime}}}^{F}-{\overline{x_{i}^{\prime} y_{i}^{\prime}}}^{P}}_{\varepsilon},
$$

with $\varepsilon$ the residual term resulting from dependencies between monthly anomalies of $x_{i}$ and $y_{i}$. Finally, since $\bar{x}^{F}=\bar{x}^{P}+\Delta \bar{x}$ and $\bar{y}^{F}=\bar{y}^{P}+\Delta \bar{y}$, one can write

$$
\Delta \overline{\mathrm{CGI}}=\underbrace{\bar{y}^{P} \Delta \bar{x}}_{\text {Dynamical }}+\underbrace{\bar{x}^{P} \Delta \bar{y}}_{\text {Thermal }}+\underbrace{\Delta \bar{x} \Delta \bar{y}+\varepsilon}_{\text {Residual }},
$$

where $\bar{y}^{P} \Delta \bar{x}$ is the contribution of dynamical changes only, and $\bar{x}^{P} \Delta \bar{y}$ is the contribution of thermal changes only. In the following, the last two terms $\Delta \bar{x} \Delta \bar{y}$ and $\varepsilon$ are grouped into a single residual term, which is systematically shown in the figures but not commented in the text. The decomposition is performed for each calendar month separately and then averaged over the season or the year.

\section{Results}

a. Analysis of high-resolution experiments

\section{1) REALism of Simulated TCS}

To assess the realism of TCs simulated by the different model configurations, we first analyze the statistical 
distribution of the annual minimum of sea level pressure in the SIO basin (Fig. 3a). Observed values are taken from IBTrACS assuming that annual minima of sea level pressure systematically occur within TCs. Over 1980-2016 the median is found to be $915 \mathrm{hPa}$; this means that such a low pressure is reached by at least one system over the SIO basin every 2 years on average. ECMWF reanalyses are unable to simulate pressures lower than $950 \mathrm{hPa}$, although a notable improvement is seen in ERA-5 relative to ERA-Interim (likely due to the increase in resolution). Uniform CNRM-CM configurations (T127 and T359) also fail to simulate extremely low pressures, although one outlying system reaches $905 \mathrm{hPa}$ in the T359 experiment. The CNRM-CM5 (CNRM-CM6-1) model nevertheless simulates lower pressures than ERA-Interim (ERA-5) while it has a slightly coarser resolution; one reason could be that in reanalyses, data assimilation tends to spatially smooth low pressure systems when centers of action are slightly shifted between assimilated observations and forecast background. The added value of the rotated-stretched configuration in the present-day climate (SIO-P) is evident from Fig. 3a: this experiment is able to simulate lower pressures than observed (e.g., below $900 \mathrm{hPa}$ ), even if the median of the annual minimum pressure distribution remains slightly higher than observed $(\sim 930 \mathrm{hPa})$.

Once the tracking is done, the realism of resulting TCs is evaluated from the statistical relationship between the minimum sea level pressure and the maximum wind speed along the track (Fig. 3b). Both variables are indeed strongly correlated, as evidenced in TC observations (IBTrACS) and shown by Atkinson and Holliday (1977). Such a relationship is well captured by presentday model experiments (T359, SIO-P), although the model exhibits stronger winds than IBTrACS for a given pressure especially in the rotated-stretched configuration. The uniform experiment (T359) nevertheless struggles to simulate strong TCs (only two systems with pressure below $930 \mathrm{hPa}$ and wind speed above $50 \mathrm{~m} \mathrm{~s}^{-1}$ ) while the rotated-stretched experiment (SIO-P) can generate stronger TCs than the most intense TC recorded in IBTrACS. This result was also found by Chauvin et al. (2020) over the North Atlantic basin. Despite its fine resolution, ERA-5 fails to reproduce the strength of observed TCs. Note that a fair comparison between winds of IBTrACS, ERA-5, and ARPEGE experiments is, however, difficult since one compares wind output at a given time step and grid point (model) with 10-min sustained winds at the local cyclone scale (IBTrACS).

Finally, a first evaluation of the projected changes in TC characteristics can be assessed from these diagnostics: here we find no clear difference in the pressurewind relationship between the SIO-P and the SIO-F
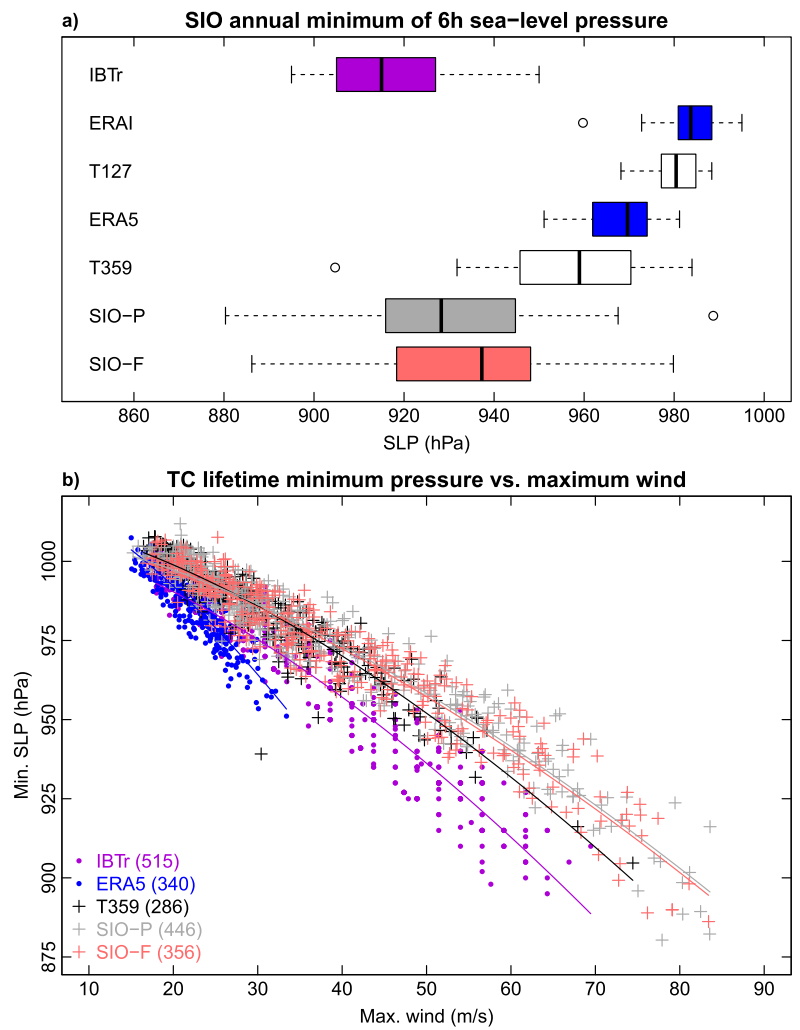

FIG. 3. (a) Distribution of the annual minimum of 6-h SLP (hPa) across the SIO domain $\left(0-30^{\circ} \mathrm{S}, 30^{\circ}-120^{\circ} \mathrm{E}\right)$ for IBTrACS (19802016, violet), ERAI and ERA5 (1980-2016, blue), T127 (19762005) and T359 (1981-2010) uniform experiments (white), and SIO-P (1971-2014, gray) and SIO-F (2051-94, red) rotatedstretched experiments. In all boxplots used in this paper, the box represents the first and third quartiles, the band inside is the median, the whiskers expand to the largest values still within the 1.5 interquartile range from the box, and the small circles indicate outliers. (b) Lifetime minimum SLP $(p)$ as function of lifetime maximum wind $(V)$ for all TCs reported in IBTrACS and detected in ERA5, T359, SIO-P, and SIO-F [periods and colors are as in (a)]. Fits are added following Atkinson and Holliday (1977) (i.e., assuming $p=a+b V^{1 / 0.644}$ with $a$ and $b$ the coefficients to be fitted).

experiments (Fig. 3b), and although the SIO-F distribution of the annual minimum of sea level pressure seems slightly shifted toward higher pressures than SIO-P (Fig. 3a), the difference between the two samples is not statistically significant ( $p$ value of about 0.5 ). Changes in TC characteristics are thus more carefully scrutinized in the following.

\section{2) ANALySis OF TC FREQUENCY}

On average, 13.9 TCs per year are reported in the SIO domain by IBTrACS (Fig. 4a). As the average number of TC days per system is found to be 5.2 days, it leads to an annual number of TC days of 73 days (Fig. 4b). The tracking algorithm has been calibrated on ERA-5 over 2011-16 (section 3); on average over these years, it 


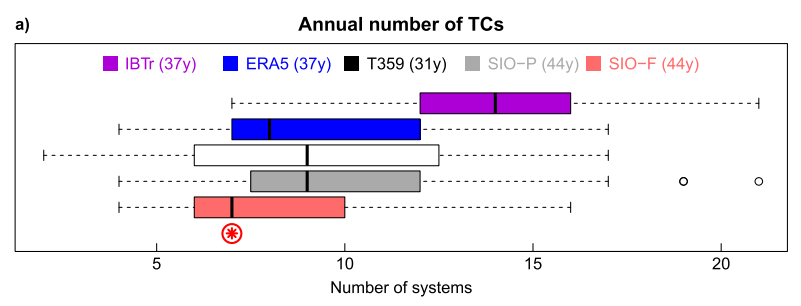

b) Annual number of TC days

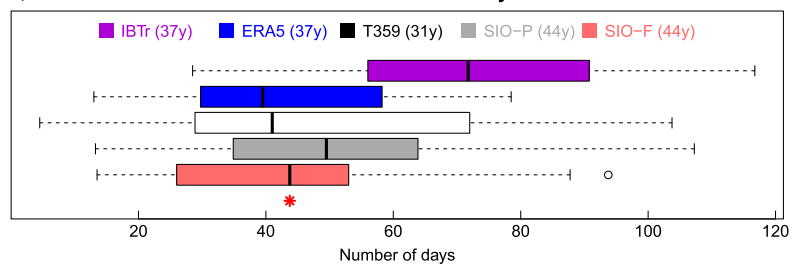

FIG. 4. (a) Distribution of the annual number of TCs in the SIO domain for IBTrACS (violet), ERA5 (blue), T359 (white), SIO-P (gray), and SIO-F (red). (b) As in (b), but for the annual number of TC days. Red (circled) asterisks indicate differences between SIO-P and SIO-F averages that are significant at the $90 \%(95 \%)$ level following a $t$ test.

detects $11 \mathrm{TCs}$ and $54 \mathrm{TC}$ days per year (vs $12.5 \mathrm{TCs}$ and 63 TC days per year in IBTrACS). Over the whole time period 1980-2016, the tracking algorithm applied to ERA-5 more substantially underestimates the observed number of both TCs ( $\left.9 \mathrm{vs} 13.9 \mathrm{yr}^{-1}\right)$ and TC days (42 vs $73 \mathrm{TC}$ days $\left.\mathrm{yr}^{-1}\right)$. This inconsistency is the strongest at the beginning of the time period and progressively decreases with time (not shown), which questions the temporal homogeneity of IBTrACS and/or ERA-5 over the SIO. However, a more detailed evaluation is left for future studies.

T359 and SIO-P experiments simulate a similar amount of TCs (9.2 and 10.1 on average, distribution in Fig. 4a) and TC days (51 vs 52 on average, distribution in Fig. 4b). This suggests that the uniform $50-\mathrm{km}$ resolution of the T359 experiment is potentially sufficient to generate a realistic number of TCs, albeit with weaker intensity than in the rotated-stretched configuration (see previous section and Fig. 3). The SIO-F experiment produces about $20 \%$ less TCs than the SIO-P experiment $\left(8.1 \mathrm{yr}^{-1}\right.$ on average), which is qualitatively consistent with the broadly reported future decrease in TC frequency (e.g., Walsh et al. 2016) and quantitatively agrees with results of Murakami et al. (2012). This $20 \%$ decrease in the frequency is significant at the $95 \%$ level; as it is associated with a slight increase in TC duration (5.5 vs 5.1 TC days per system), the decrease in the annual number of TC days in less statistically significant (90\% level, 44 vs 52 days). (This increase in TC duration is further detailed below with the TC intensity.)

In the SIO, TCs preferably develop close to the center of the basin $\left(10^{\circ}-15^{\circ} \mathrm{S}, 60^{\circ}-80^{\circ} \mathrm{E}\right)$, the Mozambique channel, and close to the Australian shore (Fig. 5a). This spatial pattern is well captured by ERA-5, confirming that the tracking algorithm applied to the reanalysis is able to detect part of the TCs reported in IBTrACS (Fig. 5b, spatial correlation of 0.90 with Fig. 5a). T359 and SIO-P experiments tend to simulate too little (much) TC intensification in the center (south) of the basin (Figs. 5c,d, spatial correlations of 0.62 and 0.51 with Fig. 5a). This might reflect a systematic bias of the CNRM-CM6-1 model since a similar behavior was reported by Chauvin et al. (2020) over the North Atlantic basin; future studies will investigate the origins of this geographical bias. The rotated-stretched configuration (SIO-P) results in an enhanced number of TCs in the SIO relative to the uniform configuration; symmetrically, less systems are simulated in other basins. A few systems have their intensification point outside the tropics (even south of $30^{\circ} \mathrm{S}$ ) in the model; these can be either systems that have developed in the tropics and reached the TC stage after an extratropical transition, or systems that have developed outside the tropics but still meet the criteria to be detected as TC by the tracking algorithm. We have decided not to filter these systems out; in particular the use of a fixed latitude criterion would have been questionable in a climate change context. A small number of such extratropical systems is also detected in ERA-5 by the tracking algorithm.

In agreement with Fig. 4, SIO-F simulates globally fewer TCs than SIO-P, especially northeast of the Mascarene Islands (Fig. 5e). Although the signal is noisy due to the limited number of systems (446 in SIO-P vs 356 in SIO-F), more TC intensification is observed south of the Mozambique and west of Australia. Similar conclusions arise from analyzing densities of full TC tracks that are smoother due to the greater number of points included (Figs. $5 \mathrm{f}-\mathrm{j}$ ). In particular, the SIO-F versus SIO-P difference reveals a general northwest-southeast dipole (with the exception of the Mozambique channel), consistent with a poleward shift of TC tracks superimposed with a general decrease in the number of TCs.

\section{3) ANALYSIS OF TC INTENSITY}

Consistent with Fig. 3b, TCs simulated by the uniform T359 experiment are weaker than reported in IBTrACS, as illustrated by both the lifetime minimum pressure (983 vs $962 \mathrm{hPa}$ on average, Fig. 6a) and maximum wind speed ( 31 vs $36 \mathrm{~m} \mathrm{~s}^{-1}$ on average, Fig. $6 \mathrm{~b}$ ). This bias is partly corrected in the rotated-stretched configuration (SIO-P, $975 \mathrm{hPa}$ and $37 \mathrm{~m} \mathrm{~s}^{-1}$ on average). TC intensity is significantly increased in the SIO-F experiment ( $971 \mathrm{hPa}$ and $39 \mathrm{~m} \mathrm{~s}^{-1}$ on average), which is again in line with the existing literature (e.g., Walsh et al. 2016). Interestingly, most of this increase in intensity arises 
a) IBTr TC intensification

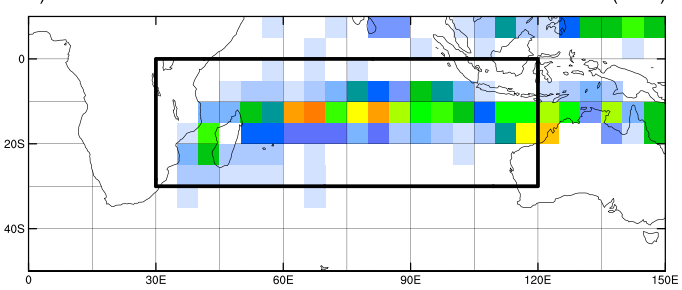

b) ERA5 TC intensification

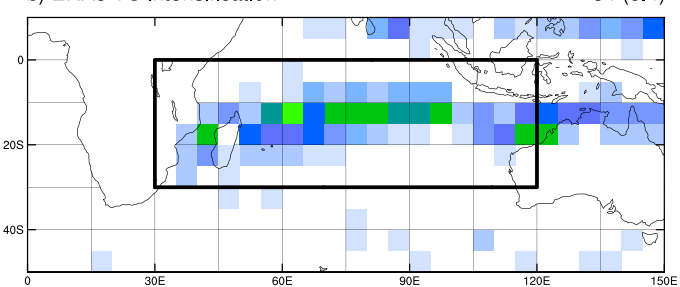

c) T359 TC intensification

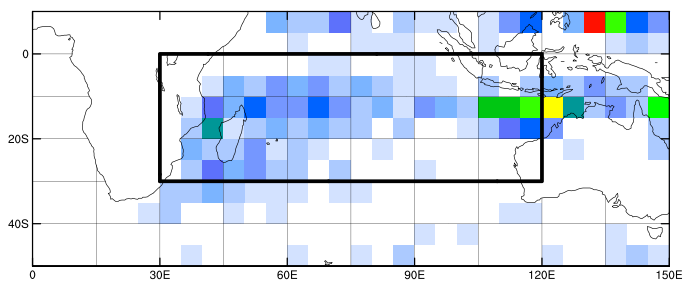

d) SIO-P TC intensification

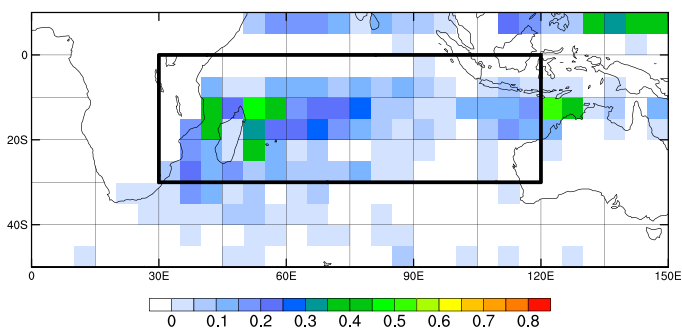

e) SIO-F TC intensification (difference wrt. SIO-P)

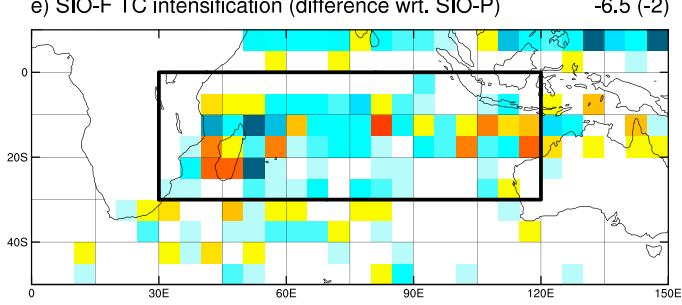

\begin{tabular}{ccccccccc}
\hline & -0.21 & -0.15 & -0.09 & -0.03 & 0.03 & 0.09 & 0.15 & 0.21
\end{tabular} f) IBTr TC tracks

$428.3(71.6)$

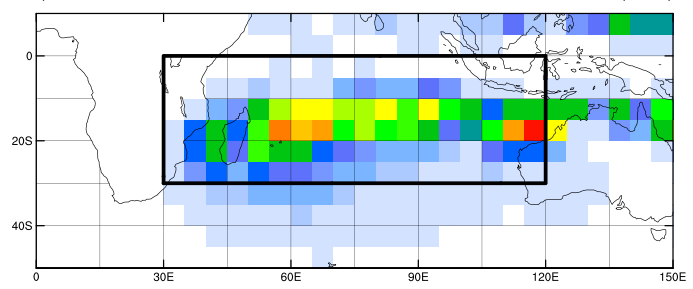

g) ERA5 TC tracks $226.8(39)$
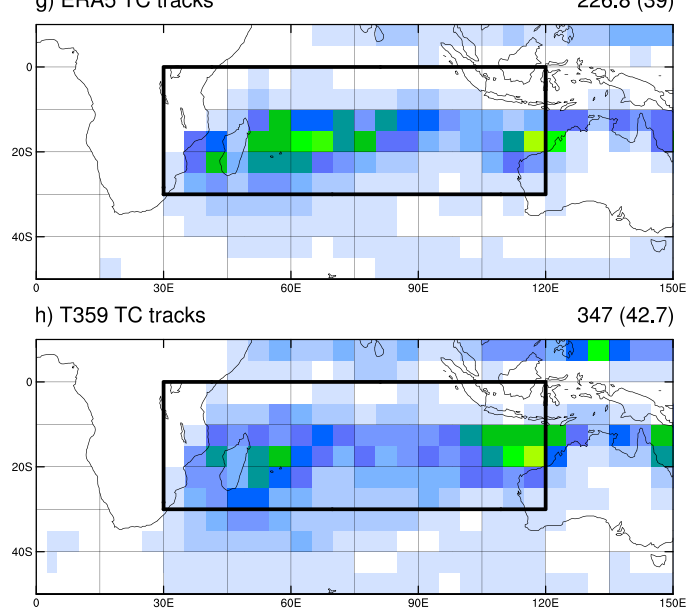

i) SIO-P TC tracks

$200(44.7)$
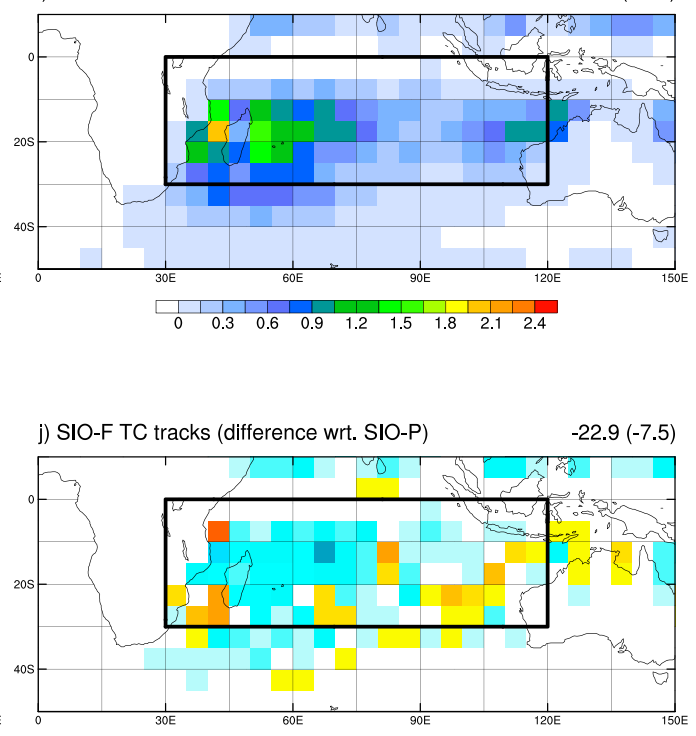

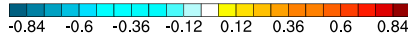

FIG. 5. (a)-(e) Frequency of TC intensification points (i.e., first TC point for each trajectory) (in number of points per year and per $5^{\circ} \times 5^{\circ}$ grid box) for (a) IBTrACS, (b) ERA5, (c) T359, (d) SIO-P, and (e) SIO-F represented as a difference relative to (d). (f)-(j) As in (a)-(e), but for TC tracks (i.e., all TC points for each trajectory). Sums over the globe and for the SIO domain (in parentheses) are indicated in the top-right corner of each panel.

from the core of the distribution: TCs with an intensity below the median of the present-day distribution occur less frequently in the future experiment $(40 \%$ of TCs in SIO-F vs $50 \%$ in SIO-P by definition), while TCs with an intensity between the 60th and 80th percentiles of the present-day distribution are more frequent $(30 \%$ vs
$20 \%$ by definition). (Values are similar for both minimum pressure and maximum wind.) Extremely intense TCs also contribute to the intensity increase: about $6 \%-$ $7 \%$ of the future TCs exceeds the 95th percentile of the present-day intensity distribution (low pressure or high winds), so that even if the overall number of TCs 

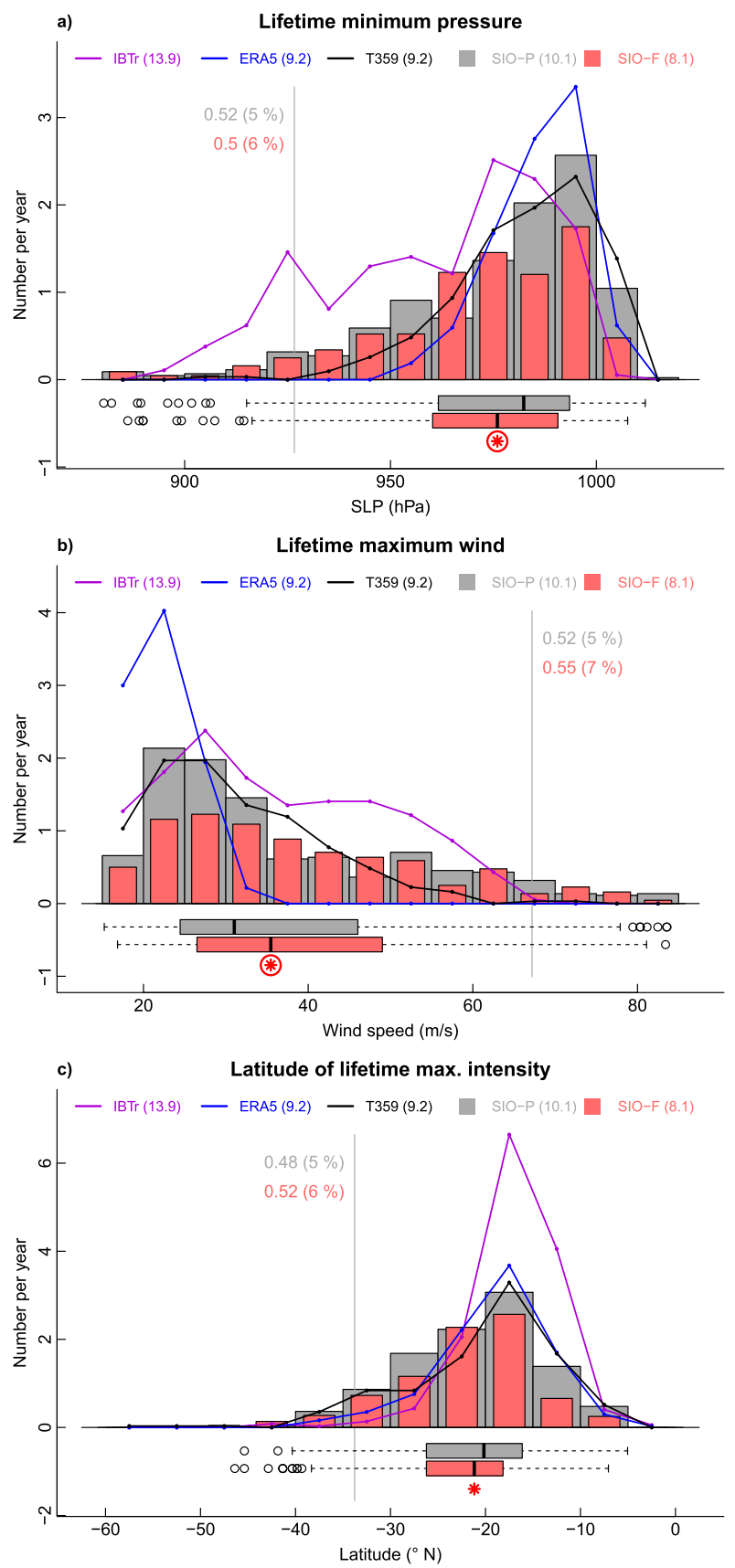

FIG. 6. (a) Frequency histogram (in number of systems per year) of the TC lifetime minimum pressure (hPa) for IBTrACS (violet line), ERA5 (blue line), T359 (black line), SIO-P (gray bars), and SIO-F (red bars). (b) As in (a), but for the lifetime maximum wind $\left(\mathrm{m} \mathrm{s}^{-1}\right)$. (c) As in (a), but for the latitude of the lifetime minimum pressure $\left({ }^{\circ} \mathrm{N}\right)$. For SIO-P and SIO-F, probability distributions are also represented (boxplots). Red (circled) asterisks indicate differences between SIO-P and SIO-F averages that are significant at the $90 \%(95 \%)$ level following a $t$ test. decreases by $20 \%$ (Fig. 4), the number of extremely intense TCs remains constant (about $0.5 \mathrm{yr}^{-1}$ with this definition). Similar results are obtained from the accumulated cyclone energy (not shown).

The increase in TC intensity in the rotated-stretched experiments is associated with a $90 \%$ level significant poleward shift of the lifetime maximum intensity (Fig. 6c). Although this is qualitatively consistent with the literature (e.g., Kossin et al. 2013), here we find a relatively weak shift of about $1^{\circ} \mathrm{S}$ in 80 years $\left(22.3^{\circ} \mathrm{S}\right.$ for SIO-F vs $21.3^{\circ} \mathrm{S}$ for SIO-P on average). This shift is related to a poleward extension of the tracks: while latitudes of genesis and intensification do not change significantly, the latitude of cyclolysis is shifted by $1.4^{\circ} \mathrm{S}$ on average $\left(26.9^{\circ}\right.$ vs $\left.25.5^{\circ} \mathrm{S}\right)$. Model biases in the spatial density of tracks (Fig. 5) are reflected in the distribution of the latitude of maximum lifetime intensity: too many (few) tracks at high (low) latitudes. Part of the discrepancy between model experiments and IBTrACS could arise from the tracking algorithm, since the ERA-5 distribution shows a similar poleward displacement.

Last, the increase in TC intensity is also related to a slightly longer TC stage (5.7 vs 5.4 days on average) that incorporates more TC days (5.5 vs 5.1 on average). Over the whole system lifetime, this increase is compensated by decreases in the duration of both development ( $1.9 \mathrm{vs}$ 2.1 days) and cyclolysis (2.4 vs 2.5 days) stages; however, only the shorter development stage is statistically significant at the $95 \%$ level (not shown). (The terminology of the different stages is defined in section 3a.)

\section{4) ANALYSIS OF SEASONAL CYCLE}

An interesting feature revealed by the rotated-stretched experiments is that the cyclone season is found to be shorter under future climate conditions (Fig. 7). In the SIO-P experiment, the first (last) TC of the season-July to June-starts on average on 12 November (28 April), so that the cyclone season-defined here as the difference between these two dates-lasts on average 172 days. These values are very close to the uniform T359 experiment (12 November to 21 April, 165 days) and to the IBTrACS observations (7 November to 28 April, 177 days). In the SIO-F experiment, the season begins on average 32 days later (14 December), ends 9 days earlier (19 April), and thus lasts 41 days less than in SIO-P. The later onset and the shorter duration of the season are significant at the $95 \%$ level. These changes result from a strong decrease in the number of TCs occurring in the austral winter: in SIO-P, 17 TCs (3.8\% on the total number) are detected during the months of June-September and $16(3.6 \%)$ in October, versus $2(0.6 \%)$ and $3(0.8 \%)$, respectively, in SIO-F. Note that such wintertime systems are realistic: 9 systems are recorded over 1980-2016 in IBTrACS in 

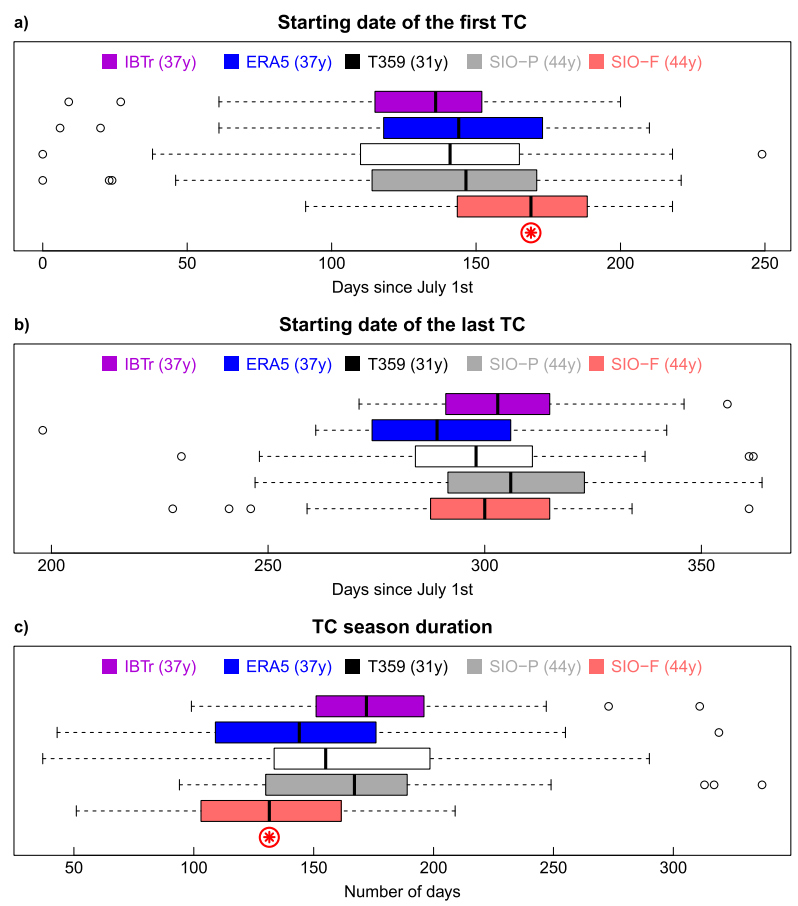

FIG. 7. As in Fig. 4, but for (a) the date of the first TC intensification within the season, (b) the date of the last TC intensification within the season, and (c) the TC season duration measured as the difference between (b) and (a).

June-September and 11 in October (i.e., $1.7 \%$ and $2.1 \%$ of the total number), with 6 systems reaching at least the severe tropical storm (category 2) stage (winds above $25 \mathrm{~m} \mathrm{~s}^{-1}$ ), including one tropical cyclone (category 3 ) system (33 $\mathrm{m} \mathrm{s}^{-1}$; Oscar in October 1983) and two intense tropical cyclone (category 4) systems $\left(47 \mathrm{~m} \mathrm{~s}^{-1}\right.$; Bellamine in October 1996 and Anais in October 2012) according to Météo-France (BoM) classifications (again, we use the terminology of the local RSMCs in this paper, not the Saffir-Simpson scale.). As a consequence of the winter decrease, the relative fraction of TCs occurring during the austral summer increases, especially during the months of February, March, and April (57\% of TCs in SIO-F vs $51 \%$ in SIO-P). Further elements about this seasonal redistribution of TCs are discussed later.

\section{b. Analysis of cyclogenesis indices}

\section{1) CGIS IN HIGH-RESOLUTION EXPERIMENTS}

Previous studies have shown that CGIs can capture the geographical distribution of cyclone activity fairly well (e.g., Menkes et al. 2012). This is verified here over the SIO basin by comparing the aggregate index (average of CGIs, see section 3) computed on the ERA-5 data (Fig. 8a) with observed TC track densities (Figs. 5a,f). CGIs are indeed able to represent both the fraction of global cyclone activity that occurs within the SIO basin (12.5 out of $84 \mathrm{TCs} \mathrm{yr}^{-1}$ on average, similar to IBTrACS values) and its spatial distribution within the basin with a local maximum around $10^{\circ} \mathrm{S}, 75^{\circ} \mathrm{E}$ (spatial correlation of 0.73 between Figs. $5 \mathrm{a}$ and $8 \mathrm{a}$ when remapped onto the same $5^{\circ} \times 5^{\circ}$ grid). The agreement between indices and actual track densities is less clear for the SIO-P experiment: CGIs suggest that cyclone activity should preferably occur within a latitudinally narrow area expanding from Madagascar to Indonesia similarly to ERA-5 (Fig. 8b) whereas TC tracks were detected more uniformly in the western part of the basin (Figs. 5d,i, spatial correlation of 0.54 between Figs. $5 \mathrm{~b}$ and $8 \mathrm{~d}$ ). Possible reasons for this discrepancy can be that (i) the native resolution in SIO-P is nonuniform across the basin, (ii) CGIs were fitted on observations and reanalysis, so that coefficients used in their computation do not reflect the model characteristics, and (iii) the model (and the tracking algorithm) seem to have difficulties to simulate (detect) TCs at low latitudes, as reported in section 4a and Fig. 5.

CGIs fail to capture the $20 \%$ decrease in TC frequency between SIO-P and SIO-F that is observed in Figs. 5e,j (Fig. 8c). They instead indicate an unchanged cyclone activity on average over the SIO basin (differ-

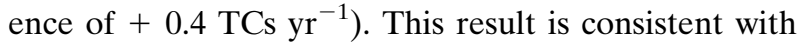
results of Chauvin et al. (2020) over the North Atlantic basin and also agrees with Camargo et al. (2014), who compared CGIs and actual TC tracks in high-resolution experiments from another model. Within the basin, the spatial pattern of changes in CGIs mostly consists in a poleward shift of the cyclone activity area, which is qualitatively consistent with changes in densities of tracks (Figs. 5e,j, spatial correlation of 0.25 between Figs. $5 \mathrm{e}$ and $8 \mathrm{c}$ ) and with the poleward displacement of the location of lifetime maximum intensity (Fig. 6c). CGIs also support an increased cyclone activity north of Madagascar and in the Mozambique channel, as seen in the TC tracks. In other words, CGIs miss the overall decrease in TC frequency but seem to capture part of the changes in the regional distribution of TC tracks.

Further, breaking down changes in CGIs into dynamical and thermal components indicates that both contribute almost equally to the poleward shift of the cyclone activity area (Figs. 8d-f). They differ the most in the western part of the basin, especially north of the Mascarene Islands, where dynamical variables support a decrease in cyclone activity-consistent with the decrease in the number of TC tracks (Fig. 5j) - which is almost entirely compensated by the thermal contribution. One could interpret such a decrease in the dynamical component as less favorable conditions for cyclogenesis (i.e., decreased TC frequency), while the 

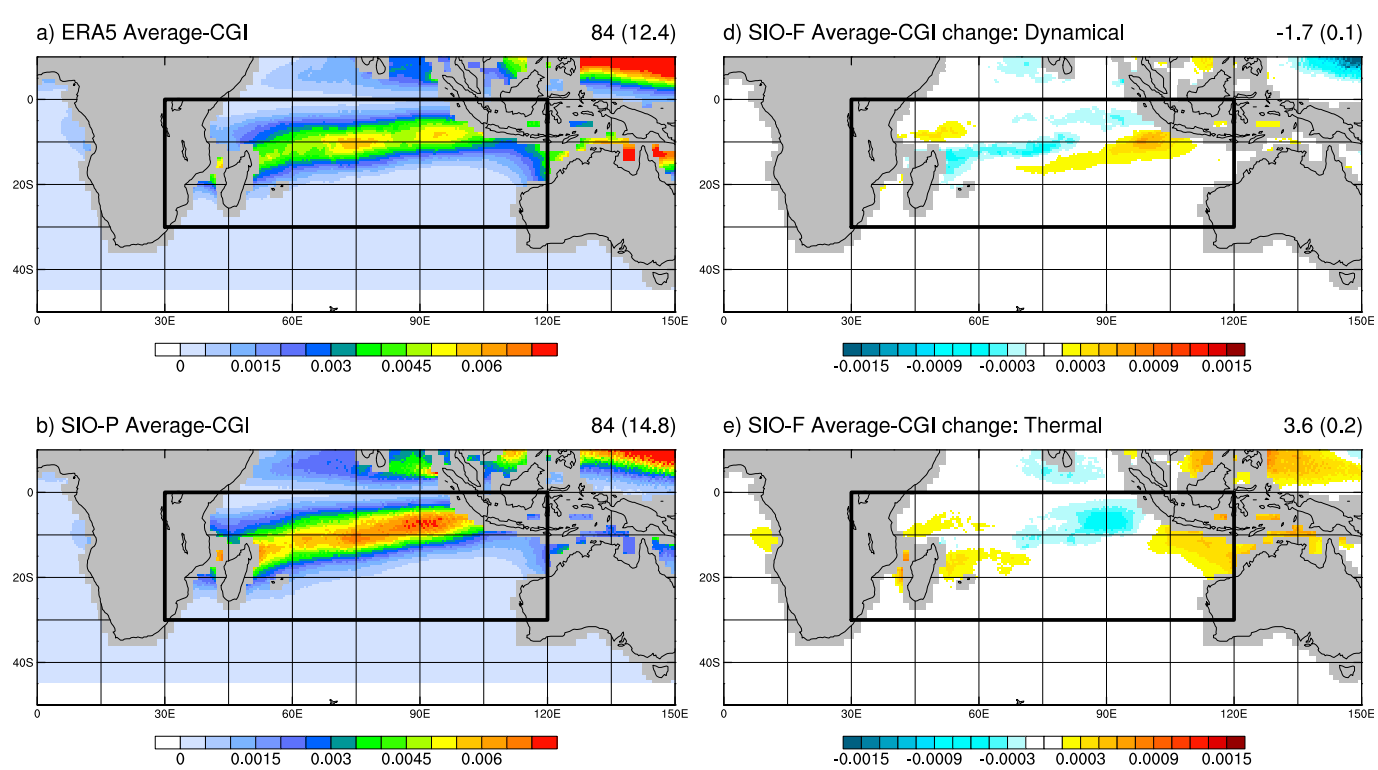

c) SIO-F Average-CGI (difference wrt. SIO-P)

$4.3(0.4)$
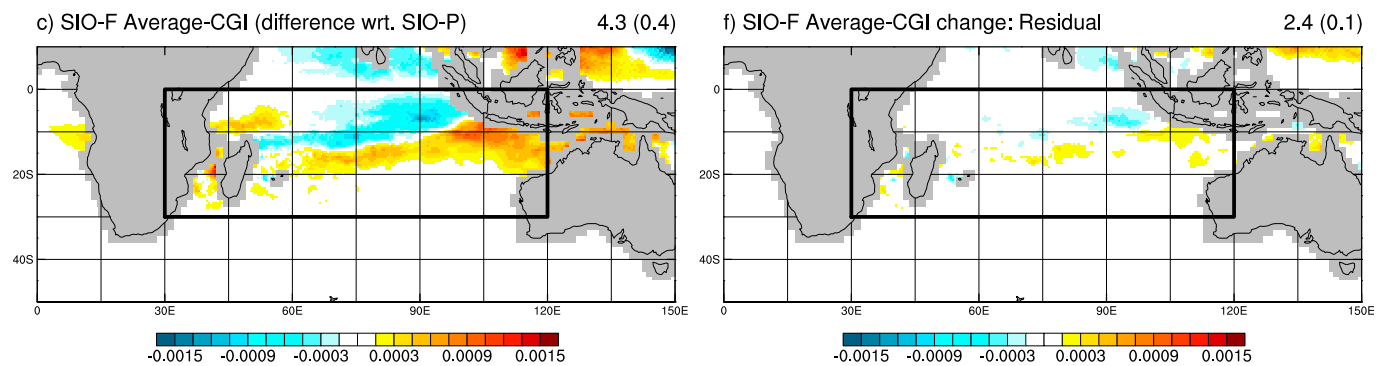

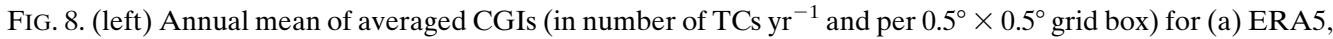
(b) SIO-P, and (c) SIO-F represented as a difference relative to (b). (right) Contributions of (d) dynamical components, (e) thermal components, and (f) residuals to (c). Sums over the globe and for the SIO domain (in parentheses) are indicated in the top-right corner of each panel.

increase in the thermal component could be indicative of more favorable conditions for intensification (i.e., increased TC intensity). However, this simple interpretation should be moderated by the fact that dynamical predictors can also be important for intensification (e.g., the vertical wind shear modulates the TC intensity), while thermal predictors can also be important for cyclogenesis (e.g., the midlevel relative humidity is relevant to spinning up the midlevel vortex in the early development). The CGI increase in the Mozambique channel solely arises from the thermal contribution, in line with a greater SST increase in this area compared to the rest of the basin (Fig. 1). The residual contribution is generally small but can be substantial especially in the eastern part of the basin.

Last, while results discussed above are based on the aggregate CGI, similar conclusions can be drawn from each index taken separately (not shown). In particular the spatial pattern of the SIO-F versus SIO-P difference (Fig. 8c) is common to all indices, albeit the spatial average over the domain differs $(+0.4,+1.3$, and -0.6 TCs per year for CYGP, GPI, and TIPP, respectively). As all the three indices share the same dynamical variables, there is little interindex dispersion in the dynamical contribution presented in Fig. 8d. Discrepancies in the thermal contribution, that is strongly positive for the GPI and slightly negative for the TIPP, therefore explain most of the differences between indices, suggesting that some thermal variables are more relevant than others to capture climate-related changes in cyclone activity.

\section{2) CGIS IN CMIP5 MODELS}

Here we assess whether changes in CGIs obtained in high-resolution CNRM-CM6-1 experiments are representative of changes in CGIs obtained in low-resolution multimodel CMIP5 projections. In the following we indicate CMIP5 ensemble-mean values together with the 10th and 90th percentiles of CMIP5 distribution between parentheses-as the ensemble contains 14 

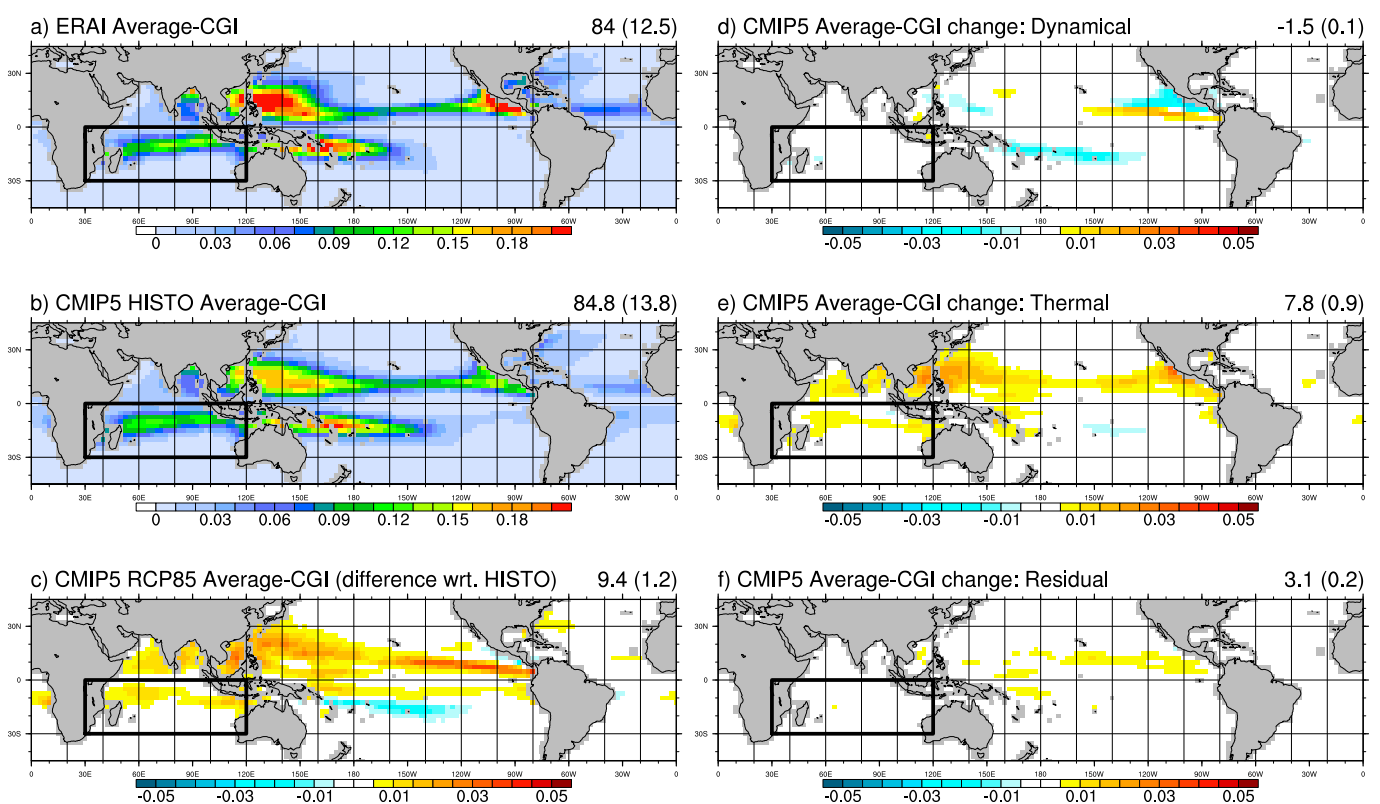

FIG. 9. (left) Annual mean of averaged CGIs (in number of $\mathrm{TCs}^{-1} \mathrm{r}^{-1}$ and per $2.5^{\circ} \times 2.5^{\circ}$ grid box) for (a) ERAI, (b) CMIP5 ensemble mean historical simulations over 1976-2005, and (c) CMIP5 ensemble-mean RCP8.5 simulations over 2070-99 represented as a difference relative to (b). (right) Contributions of (d) dynamical components, (e) thermal components, and (f) residuals to (c). Sums over the globe and for the SIO domain (in parentheses) are indicated in the top-right corner of each panel.

models, this range excludes the two lowest and two highest values.

First, comparing ERA-Interim $(80-\mathrm{km}$ resolution, interpolated onto a $2.5^{\circ}$ grid, Fig. 9a) with ERA-5 (30-km resolution, interpolated onto a $0.5^{\circ}$ grid, Fig. $8 \mathrm{a}$ ) shows that the resolution has little effect on the computation of CGIs; this was expected since these indices are designed to account for large-scale conditions. Both reanalyses indeed result in a similar fraction of cyclone activity in the SIO (about $15 \%$ of the global activity) and a similar spatial pattern within the basin. CMIP5 models have been shown to represent the geographical climatology of several CGIs fairly well (Camargo 2013), which is here confirmed by our aggregate CGI (Fig. 9b), although the ensemble averaging tends to smooth hotspots of cyclone activity due to intermodel dispersion in the exact location of local maxima. On average, about $16 \%[14 \%-20 \%]$ of the global cyclone activity occurs in the SIO, which is consistent with reanalyses. [A more detailed analysis of individual CMIP5 model biases can be found in Camargo (2013) and is considered to be beyond the scope of this paper.] Importantly, we have verified that our SIO-P high-resolution experiment lies within the range of CMIP5 models in terms of representation of present-day climatology of CGIs (not shown).

In future RCP8.5 projections, CMIP5 models simulate an overall increase in CGIs, slightly less pronounced over the $\mathrm{SIO}(+9 \%[-8 \%$ to $20 \%])$ than globally $(+11 \%$ [ $-2 \%$ to $20 \%$ ], Fig. 9 c). Our results based on an aggregate CGI are consistent with the GPI analysis reported in Camargo (2013), although the GPI is the index that projects the strongest ensemble-mean increase: $+16.3(+2.8)$ TCs per year at global scale (in the SIO basin) versus $+7.7(+0.2)$ and $+4.1(+0.6)$ for the CYGP and the TIPP, respectively.

The global increase in CGIs projected by CMIP5 models $(+11 \%$, i.e., +9.4 TCs per year) arises from the thermal contribution $(+7.8$ TCs per year), while the dynamical component exhibits a small decrease $(-1.5$, Figs. $9 \mathrm{~d}-\mathrm{f})$. The latter is robust across indices $(-2,-1.2$, and -1.3 for CYGP, GPI, and TIPP, respectively), while the former is the strongest for GPI $(+14.7)$ and the lowest for TIPP $(+3)$. This is consistent with CGIs applied to high-resolution experiments and supports the idea that changes in dynamical conditions could be related to changes in TC frequency (e.g., less favorable weather for cyclogenesis), while changes in thermal conditions could be related to changes in TC intensity (e.g., more available energy for intensification). This may be particularly the case for the GPI that includes the potential intensity introduced by Emanuel (1988) in its thermal component (Emanuel and Nolan 2004). Again, this interpretation should nevertheless be moderated because the relationship between dynamical versus thermal components and TC genesis versus intensification is not straightforward. 

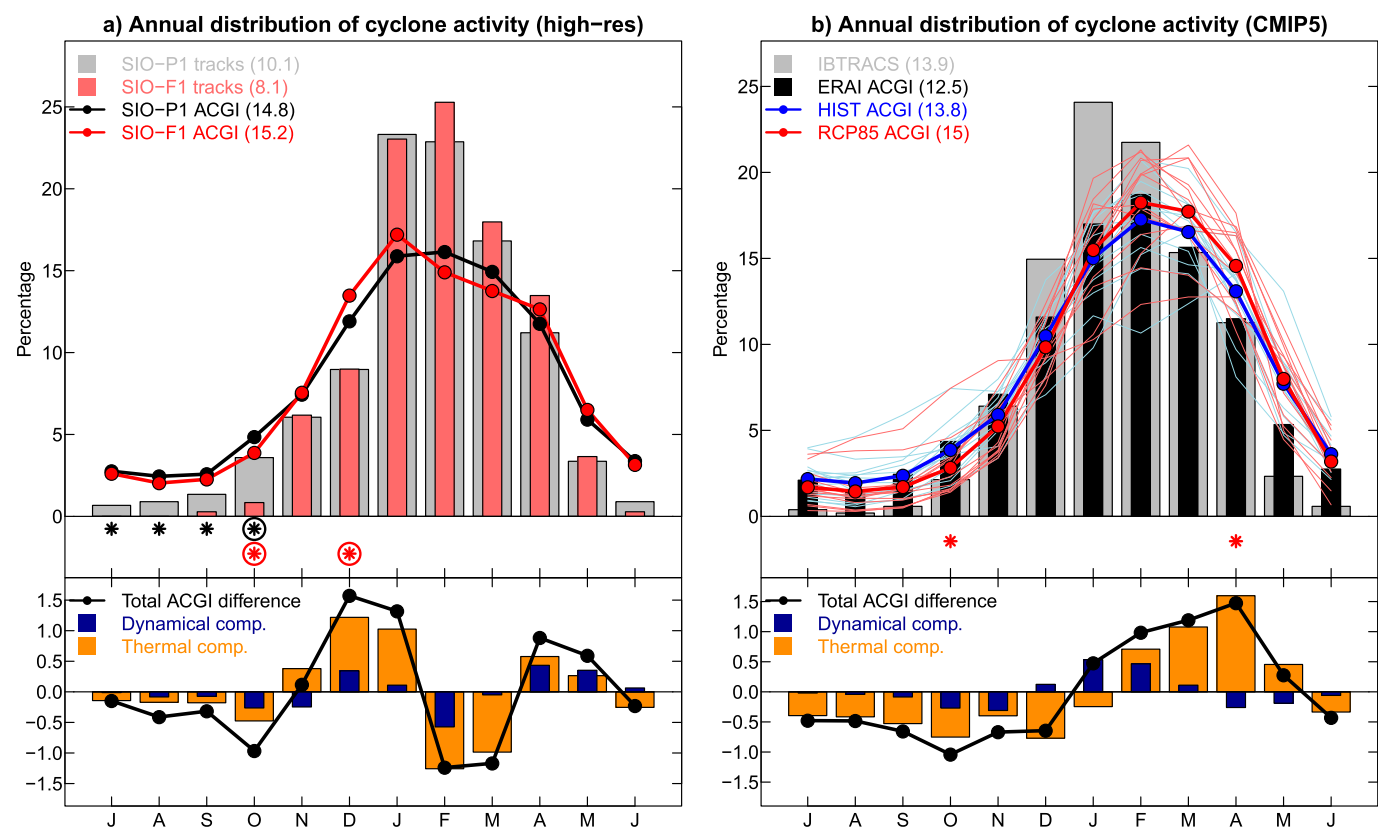

FIG. 10. (a) Annual distribution of SIO-P (gray bars) and SIO-F (red bars) TCs, and SIO-P (black line) and SIO-F (red line) aggregate CGI. Black (circled) asterisks indicate differences between bars that are significant at the $90 \%$ (95\%) level; red (circled) asterisks indicate differences between lines that are significant at the $90 \%$ (95\%) level. (b) Annual cycle of IBTrACS TCs (gray bars), and ERA-Interim (black bars), CMIP5 historical (blue lines), and RCP8.5 (red lines) averaged CGIs, with thick lines for ensemble means. Red (circled) asterisks indicate differences between ensemble means that are significant at the $90 \%$ (95\%) level. All cycles are normalized and represented in percent per month. (bottom) Decomposition of the total aggregate CGI difference (black line) into dynamical (blue bars) and thermal (orange bars) components.

With a +0.4 TCs per year increase in the SIO (Fig. 8c), the SIO-F versus SIO-P difference is consistent with the range of CMIP5 projections. A fair comparison is, however, difficult since time periods used to evaluate changes differ. Interestingly, spatial patterns of CGI changes in the SIO are similar between high-resolution CNRM-CM6-1 experiments and the CNRM-CM5 experiment included in the CMIP5 ensemble (not shown). This is not completely surprising since SIO-P and SIO-F experiments use SST taken from this CNRM-CM5 simulation, but suggests that changes in large-scale environmental variables associated with cyclone activity are robust across the two versions of the atmospheric model and the two grid configurations. The poleward shift of cyclone activity suggested by CNRM-CM6-1 aggregate CGIs is, however, not representative of the CMIP5 ensemble that rather projects a reinforcement of cyclone activity close to the equator (Fig. 9c). This highlights that changes in the geographical distribution of cyclone activity captured by CGIs can be model dependent (e.g., Camargo 2013).

\section{3) ANALysis of CGIs' ANNUAl CyCLE}

Globally, CGIs have been shown to represent the annual cycle of TC occurrence fairly well, although with a weaker seasonal amplitude (Menkes et al. 2012). This is confirmed here by our high-resolution exeriments: in the SIO-P experiment, $90 \%$ of the TC tracks occur from November to May while the aggregate CGI would indicate $78 \%$ (Fig. 10a). As discussed above (Fig. 7), we find a dramatic decrease in TC frequency during the austral winter in the SIO-F experiment, which translates into a significant decrease in the relative TC occurrence from June to October, counterbalanced by an increase-albeit not significant-from February to April. This redistribution is partly explained by CGIs, which also support a relative decrease of cyclone activity in winter (significant in October) and a relative increase in summer (significant in December). The fact that relative changes disagree between TC tracks and CGIs in February and March could be due to sampling uncertainty since they are not statistically significant.

Annual cycles of both TC occurrence and CGIs simulated by the SIO-P experiment are consistent with IBTrACS and ERA-Interim, respectively (Fig. 10b). In particular, $94 \%$ of IBTrACS TCs occur from November to May while the ERA-Interim aggregate CGI would indicate $82 \%$. CMIP5 historical simulations are generally consistent with ERA-Interim in that aspect, 
although they tend to underestimate (overestimate) the proportion of cyclone activity in early (late) summer: $49 \%(41 \%)$ from November to February (March to June) on average over the ensemble versus 54\% (35\%) in ERA-Interim. Projected changes in the RCP8.5 simulations are indicative of relative decrease of cyclone activity from June to December (significant in October) counterbalanced by a relative increase from January to May (significant in April). Such a seasonal redistribution of cyclone activity is fully consistent with results from our high-resolution experiments, suggesting that this feature of TC changes could be robust across models. Last, both dynamical and thermal components contribute to reshaping the annual cycle of CGIs, although monthly contributions differ: for instance, in CMIP5, the CGI relative increase in summer is mostly explained by the dynamical component in January, by the thermal component in March and April, and by both in February.

\section{Discussion}

In this paper we have tried to assess projected changes in the SIO cyclone activity from two complementary approaches: (i) high-resolution experiments with our inhome model (CNRM-CM6-1) that simulates realistic TCs and allows for a statistical analysis of TC characteristics and (ii) low-resolution multimodel climate projections in which cyclone activity can only be estimated from empirical indices built on large-scale environmental variables. Although we have shown that robust results emerge, both approaches used in this study suffer from clear limitations.

First, our high-resolution experiments are performed in an atmosphere-only framework (i.e., with prescribed SST), whereas the atmosphere strongly interacts with the near-surface ocean during TCs. Daloz et al. (2012) have shown that the ocean-atmosphere coupling can modify the simulation of TCs by the rotated-stretched configuration of the CNRM-CM model, the impact being sensitive to the coupling frequency. However, in their review paper, Walsh et al. (2016) assess that atmosphere-ocean coupling only has a limited effect on climate change experiments. In addition, using an atmosphere-only framework allows us to correct for potential biases in SST (as done in our experimental design).

Second, results obtained with the rotated-stretched configuration might be sensitive to the arbitrary choice of the grid pole location (Daloz et al. 2012). In the present study, the focus has been intentionally made on the western part of the SIO, in order to better assess potential changes in TCs over the area enclosing Mozambique, Madagascar, and the Mascarene Islands [i.e., the region under the responsibility of Météo-France (local RSMC)]. In exchange, the resolution was not dramatically increased at the other side of the SIO (Australian shore) compared to the uniform T359 grid. We are nevertheless confident (from our expertise with the rotated-stretched configuration) that a small displacement of the grid pole would not have altered the results significantly. The fact that the uniform T359 experiment $(50 \mathrm{~km})$ simulates reasonable TCs gives us additional confidence that results of rotated-stretched experiments are robust across the whole SIO basin. Last, our results share some similarities with Chauvin et al. (2020), which suggests that the main conclusions could be robust among oceanic basins, although a more systematic analysis would be needed.

A third limitation of our experimental protocol is that it only includes one member per experiment, which could raise questions about our ability to disentangle climate change signal from the noise of internal variability. More ensemble members would probably have smoothed the changes in track densities presented in Fig. 5; we were nevertheless able to detect a few statistically significant changes at the basinwide scale, such as the decrease in the overall number of TCs or the reduction in the duration of the cyclone season. In their analysis of the North Atlantic basin, Chauvin et al. (2020) performed five members per experiment and concluded that although this provides robustness in results obtained at regional scale, one member of 50 years is sufficient for the large-scale signal to emerge.

A follow-up question is the sensitivity of our results to the unique model used to perform high-resolution experiments (CNRM-CM6-1). Here we have shown that (i) our results are quantitatively similar to other highresolution modeling studies (e.g., Murakami et al. 2012) and that (ii) large-scale environmental changes simulated by CNRM-CM6-1 lie in the range of CMIP5 uncertainties. However, the issue of model dependency will not be properly tackled until multimodel ensembles of high-resolution climate projections exist, and the upcoming HighResMIP exercise (Haarsma et al. 2016) can be considered as a promising first step to that regard.

Last, statistical tools used to analyze both highresolution experiments (TC tracking algorithm) and multiple low-resolution model datasets (computation of CGIs) can be questioned. The TC tracking algorithm uses several arbitrary thresholds (winds, vorticity, temperature) that clearly affect the number of systems detected; however, we have verified that our main findings remain unchanged when using slightly different thresholds (not shown). The computation of CGIs is also problematic as the choice of the predictors (environmental variables) and the fit of their coefficients are likely to be model 
sensitive; using 3 indices and 14 models was a way to take this source of uncertainty into account, and building more sophisticated and possibly model-dependent CGIs is left for future work.

\section{Conclusions}

The aim of this study was to assess projected changes in the SIO tropical cyclone (TC) activity from both high-resolution CNRM-CM6-1 dedicated experiments and CMIP5 multimodel climate projections. Our main findings can be summarized as follows:

- the uniform T359 $(50 \mathrm{~km})$ configuration of the CNRMCM6-1 model is able to simulate realistic TCs in terms of frequency and pressure-wind relationship, although with a weaker intensity than observed. The rotatedstretched configuration improves the realism of simulated TCs (especially in terms of intensity) over the area of interest.

- Rotated-stretched high-resolution experiments project a $20 \%$ decrease in the SIO TC frequency between 19652014 and 2045-94 in the RCP8.5 scenario. In the meantime, they indicate an increase in the maximum lifetime intensity, and a slight poleward extension of the TC tracks. As a consequence, the frequency of the strongest TCs is projected to remain nearly constant.

- Rotated-stretched high-resolution experiments project a substantial reduction of the cyclone season duration; in particular the first TC of the season is projected to occur 1 month later on average (mid-December vs mid-November). Although the raw number of TCs is projected to decrease for all individual months, cyclone activity is redistributed within the season, with a smaller (greater) relative proportion of cyclones occurring in early (late) summer. This result may be important for Regional Specialized Meteorological Centres and local administrations in charge of TC monitoring and alertness. - Cyclogenesis indices (CGIs) applied to high-resolution experiments fail to capture the projected decrease in overall TC frequency. However, they are able to partially represent changes in the spatiotemporal distribution of cyclone activity, such as the poleward shift and the seasonal redistribution. This may not be surprising as CGIs are designed to represent not the total number of TCs but their spatiotemporal distribution.

- Changes in CGIs obtained from CNRM-CM6-1 lie in the range of CMIP5 projections. In particular the seasonal redistribution of cyclone activity is consistent across models.

Future work will involve further understanding of the decreasing TC frequency in CNRM-CM6-1 experiments: whether this results from less frequent initiations of small-scale vortices or from less favorable conditions to intensification into TCs will be particularly scrutinized in the light of the work of Duvel (2015). Besides, the computation of CGIs in high-resolution experiments can be viewed as a first step into the physical understanding of changes in cyclone activity, and future analyses will further explore how they relate to changes in large-scale environmental features such as the Indian monsoon, the Madden-Julian oscillation, and/or the Hadley-Walker circulation. Impact studies may also be conducted to assess consequences of the projected changes in cyclone activity on associated phenomena such as rainfall or storm surges. Expanding the analysis to the new generation of climate models (CMIP6) — especially those with sufficiently high resolutions to simulate realistic TCs-will also be naturally considered for future work.

Finally, a promising prospective of this study is to pursue the efforts to reconcile results on TCs derived from high-resolution experiments with CGIs computed on low-resolution climate projections. In this paper we have shown that although CGIs miss the overall decrease in the number of TCs, they partially capture changes in their spatiotemporal distribution. Further, we have shown that the future increase in CGIs is mostly driven by their thermal component, while their dynamical component slightly decreases. The fact that these indices are empirically fitted on present-day cyclone activity features might give too much weight to the thermal component in a climate change context. Future research may therefore focus on the development of cyclogenesis indices that remain relevant for assessing climate change, taking advantage of high-resolution climate projections distributed within CMIP6 and possibly using more comprehensive statistical learning techniques.

Acknowledgments. This work has been partly supported by the ReNovRisk-C3 project within the Indian Ocean INTERREG-V Programme 2014-20. J.C. thanks all people at LACy and Météo-France La Réunion for their welcome and fruitful discussions, and Rémy LeeAh-Siem for technical support.

\section{REFERENCES}

Atkinson, G., and C. Holliday, 1977: Tropical cyclone minimum sea level pressure/maximum sustained wind relationship for the western North Pacific. Mon. Wea. Rev., 105, 421-427, https:// doi.org/10.1175/1520-0493(1977)105<0421:TCMSLP>2.0.CO;2.

Camargo, S., 2013: Global and regional aspects of tropical cyclone activity in the CMIP5 models. J. Climate, 26, 9880-9902, https://doi.org/10.1175/JCLI-D-12-00549.1. 
— M. Tippett, A. Sobel, G. Vecchi, and M. Zhao, 2014: Testing the performance of tropical cyclone genesis indices in future climates using the HiRAM model. J. Climate, 27, 9171-9196, https://doi.org/10.1175/JCLI-D-13-00505.1.

Chauvin, F., J.-F. Royer, and M. Déqué, 2006: Response of hurricane-type vortices to global warming as simulated by ARPEGE-Climat at high resolution. Climate Dyn., 27, 377399, https://doi.org/10.1007/s00382-006-0135-7.

_ , R. Pilon, P. Palany, and A. BelMadani, 2020: Future changes in Atlantic hurricanes with the rotated-stretched ARPEGEClimat at very high resolution. Climate Dyn., 54, 947-972, https://doi.org/10.1007/s00382-019-05040-4.

Daloz, A. S., F. Chauvin, and F. Roux, 2012: Impact of the configuration of stretching and ocean-atmosphere coupling on tropical cyclone activity in the variable-resolution GCM ARPEGE. Climate Dyn., 39, 2343-2359, https://doi.org/10.1007/s00382-012-1561-3.

Dee, D., and Coauthors, 2011: The ERA-Interim reanalysis: Configuration and performance of the data assimilation system. Quart. J. Roy. Meteor. Soc., 137, 553-597, https://doi.org/ 10.1002/qj.828.

Duvel, J.-P., 2015: Initiation and intensification of tropical depressions over the southern Indian Ocean: Influence of the MJO. Mon. Wea. Rev., 143, 2170-2191, https://doi.org/10.1175/ MWR-D-14-00318.1.

Emanuel, K., 1988: The maximum intensity of hurricanes. J. Atmos. Sci., 45, 1143-1155, https://doi.org/10.1175/1520-0469(1988) 045<1143:TMIOH $>2.0$. CO; 2 .

—_, and D. Nolan, 2004: Tropical cyclone activity and the global climate system. Preprints, 26th Conf. on Hurricanes and Tropical Meteorology, Miami, FL, Amer. Meteor. Soc., 240-241.

Gray, W. M., 1975: Tropical cyclone genesis. Atmospheric Science Paper 234, Colorado State University, $121 \mathrm{pp}$.

Haarsma, R., and Coauthors, 2016: High Resolution Model Intercomparison Project (HighResMIP v1.0) for CMIP6. Geosci. Model Dev., 9, 4185-4208, https://doi.org/10.5194/ gmd-9-4185-2016.

Held, I., and M. Zhao, 2011: The response of tropical cyclone statistics to an increase in $\mathrm{CO}_{2}$ with fixed sea surface temperatures. J. Climate, 24, 5353-5364, https://doi.org/10.1175/ JCLI-D-11-00050.1.

Hersbach, H., and Coauthors, 2018: Operational global reanalysis: Progress, future directions and synergies with NWP. ERA Rep. Series 27, 65 pp, https://doi.org/10.21957/tkic6g3wm.

Holland, G., and C. Bruyère, 2014: Recent intense hurricane response to global climate change. Climate Dyn., 42, 617-627, https://doi.org/10.1007/s00382-013-1713-0.

Knapp, K., M. Kruk, D. Levinson, H. Diamond, and C. Neumann, 2010: The International Best Track Archive for Climate Stewardship (IBTrACS). Bull. Amer. Meteor. Soc., 91, 363 376, https://doi.org/10.1175/2009BAMS2755.1.

Knutson, T., and Coauthors, 2010: Tropical cyclones and climate change. Nat. Geosci., 3, 157-163, https://doi.org/10.1038/ngeo779.

—, J. Sirutis, M. Zhao, R. Tuleya, M. Bender, G. Vecchi, G. Villarini, and D. Chavas, 2015: Global projections of intense tropical cyclone activity for the late twenty-first century from dynamical downscaling of CMIP5/RCP4.5 scenarios. J. Climate, 28, 7203-7224, https://doi.org/10.1175/JCLI-D-15-0129.1.

Kossin, J., 2018: A global slowdown of tropical-cyclone translation speed. Nature, 558, 104-107, https://doi.org/10.1038/s41586018-0158-3.

— T. Olander, and K. Knapp, 2013: Trend analysis with a new global record of tropical cyclone intensity. J. Climate, 26, 9960-9976, https://doi.org/10.1175/JCLI-D-13-00262.1.
Kuleshov, Y., R. Fawcett, L. Qi, B. Trewin, D. Jones, J. McBride, and H. Ramsay, 2010: Trends in tropical cyclones in the South Indian Ocean and the South Pacific Ocean. J. Geophys. Res., 115, D01101, https://doi.org/10.1029/2009JD012372.

Malan, N., C. Reason, and B. Loveday, 2013: Variability in tropical cyclone heat potential over the Southwest Indian Ocean. J. Geophys. Res. Oceans, 118, 6734-6746, https://doi.org/ 10.1002/2013JC008958.

Menkes, C., M. Lengaigne, P. Marchesiello, N. Jourdain, E. Vincent, J. Lefèvre, F. Chauvin, and J.-F. Royer, 2012: Comparison of tropical cyclogenesis indices on seasonal to interannual timescales. Climate Dyn., 38, 301-321, https://doi.org/10.1007/ s00382-011-1126-x.

Murakami, H., and Coauthors, 2012: Future changes in tropical cyclone activity projected by the new high-resolution MRIAGCM. J. Climate, 25, 3237-3260, https://doi.org/10.1175/ JCLI-D-11-00415.1.

Peng, M., B. Fu, T. Li, and D. Stevens, 2012: Developing versus nondeveloping disturbances for tropical cyclone formation. Part I: North Atlantic. Mon. Wea. Rev., 140, 1047-1066, https://doi.org/10.1175/2011MWR3617.1.

Rayner, N. A., D. Parker, E. Horton, C. Folland, L. Alexander, D. Rowell, E. Kent, and A. Kaplan, 2003: Global analyses of sea surface temperature, sea ice, and night marine air temperature since the late nineteenth century. J. Geophys. Res., 108, 4407, https://doi.org/10.1029/2002JD002670.

Royer, J.-F., and F. Chauvin, 2009: Response of tropical cyclogenesis to global warming in an IPCC AR4 scenario. Hurricanes and Climate Change, J. Elsner and T. Jagger, Eds., Springer, 213-234, https://doi.org/10.1007/978-0-387-09410-6_12.

, — - B. Timbal, P. Araspin, and D. Grimal, 1998: A GCM study of the impact of greenhouse gas increase on the frequency of occurrence of tropical cyclones. Climatic Change, 38, 307-343, https://doi.org/10.1023/A:1005386312622.

Sugi, M., H. Murakami, and J. Yoshimura, 2012: On the mechanism of tropical cyclone frequency changes due to global warming. J. Meteor. Soc. Japan, 90A, 397-408, https://doi.org/10.2151/ JMSJ.2012-A24.

Taylor, K., R. Stouffer, and G. Meehl, 2011: An overview of CMIP5 and the experiment design. Bull. Amer. Meteor. Soc., 93, 485498, https://doi.org/10.1175/BAMS-D-11-00094.1.

Tippett, M., S. Camargo, and A. Sobel, 2011: A Poisson regression index for tropical cyclone genesis and the role of large-scale vorticity in genesis. J. Climate, 24, 2335-2357, https://doi.org/ 10.1175/2010JCLI3811.1.

Voldoire, A., and Coauthors, 2013: The CNRM-CM5. 1 global climate model: Description and basic evaluation. Climate Dyn., 40, 2091-2121, https://doi.org/10.1007/s00382-011-1259-y.

— , and Coauthors, 2019: Evaluation of CMIP6 DECK experiments with CNRM-CM6-1. J. Adv. Model. Earth Syst., 11, 2177-2213, https://doi.org/10.1029/2019MS001683.

Walsh, K., and Coauthors, 2016: Tropical cyclones and climate change. Wiley Interdiscip. Rev.: Climate Change, 7, 65-89, https://doi.org/10.1002/WCC.371.

Wehner, M., Prabhat, K. A. Reed, D. Stone, W. D. Collins, and J. Bacmeister, 2015: Resolution dependence of future tropical cyclone projections of CAM5.1 in the U.S. CLIVAR Hurricane working group idealized configurations. J. Climate, 28, 3905-3925, https://doi.org/10.1175/JCLI-D-14-00311.1.

Woodruff, J., J. Irish, and S. Camargo, 2013: Coastal flooding by tropical cyclones and sea-level rise. Nature, 504, 44-52, https:// doi.org/10.1038/nature12855. 
Copyright of Journal of Climate is the property of American Meteorological Society and its content may not be copied or emailed to multiple sites or posted to a listserv without the copyright holder's express written permission. However, users may print, download, or email articles for individual use. 